CENTRO UNIVERSITÁRIO FEI

Rafael Hideki Yamato

\begin{abstract}
AVALIAÇÃO DO DESEMPENHO DE UM SISTEMA PRODUTO-SERVIÇO (PSS) DE UMA EMPRESA DE REFEIÇÕES COLETIVAS SOB O FOCO DA SUSTENTABILIDADE
\end{abstract}

São Bernardo do Campo 2019 
RAFAEL HIDEKI YAMATO

\section{AVALIAÇÃO DO DESEMPENHO DE UM SISTEMA PRODUTO-SERVIÇO (PSS) DE UMA EMPRESA DE REFEIÇÕES COLETIVAS SOB O FOCO DA SUSTENTABILIDADE}

Dissertação de Mestrado apresentada ao Centro Universitário FEI para obtenção do título de Mestre em Engenharia Mecânica - área de concentração: Produção - orientada pelo Prof. Dr. Dário Henrique Alliprandini.

São Bernardo do Campo 
Yamato, Rafael Hideki.

Avaliação do desempenho de um sistema produto-serviço (PSS) de uma empresa de refeições coletivas sob o foco da sustentabilidade / Rafael Hideki Yamato. São Bernardo do Campo, 2019.

69 f. : il.

Dissertação - Centro Universitário FEI.

Orientador: Prof. Dr. Dário Henrique Alliprandini.

1. Sistemas produto-serviço. 2. Sustentabilidade. 3. Desempenho. 4. Serviço de refeições coletivas. I. Alliprandini, Dário Henrique, orient. II. Título.

Elaborada pelo sistema de geração automática de ficha catalográfica da FEI com os dados fornecidos pelo(a) autor(a). 
Aluno: Rafael Hideki Yamato

Matrícula: 216126-3

Título do Trabalho: Avaliação do desempenho de um sistema produto-serviço (pss) de uma empresa de refeições coletivas sob o foco da sustentabilidade.

Área de Concentração: Produção

Orientador: Prof. Dr. Dário Henrique Alliprandini

Data da realização da defesa: 26/02/2019

\section{ORIGINAL ASSINADA}

\section{Avaliação da Banca Examinadora:}

São Bernardo do Campo,

\section{MEMBROS DA BANCA EXAMINADORA}

Prof. Dr. Dário Henrique Alliprandini

Prof. Dr. Alexandre Augusto Massote

Profa. Dra. Veridiana Rotondaro Pereira
Ass.:

Ass.:

Ass.:

A Banca Julgadora acima-assinada atribuiu ao aluno o seguinte resultado: APROVADO $\bigotimes$ REPROVADO

\section{VERSÃO FINAL DA DISSERTAÇÃO}

APROVO A VERSÄO FINAL DA DISSERTAÇÄO EM QUE FORAM INCLUÍDAS AS RECOMENDAÇÔES DA BANCA EXAMINADORA
Aprovação do Coordenador do Programa de Pós-graduação

Prof. Dr. Rodrigo Magnabosco 


\section{RESUMO}

O sistema produto-serviço (PSS) é uma oferta de produto e serviço integrados que entregam valor e tem potencial de conduzir ao consumo sustentável de recursos, focando na redução dos fluxos de materiais na produção e também na criação de produtos e serviços que ofereçam aos clientes o mesmo nível de desempenho por meio de cenários alternativos de uso do produto, do aumento da produtividade global de recursos e da desmaterialização. O setor de alimentos retrata essa complexidade pois é composto por diferentes fases como produção, processamento, transporte e armazenamento até a fase de uso-consumo oferecendo desafios nos âmbitos ambientais, econômicos e sociais, pois o PSS representa uma família de modelo de negócio com foco na sustentabilidade, destinados a satisfazer as necessidades sociais de uma forma econômica e ambientalmente sustentável. O objetivo da pesquisa foi analisar os indicadores da sustentabilidade a partir de cenários operacionais e estratégicos de um sistema produtoserviço de uma empresa de refeições coletivas. Para isso, construiu-se um modelo de simulação capaz de retratar o desempenho dos cenários do sistema e apoiar na avaliação dos indicadores. Como resultado, entendeu-se que o desempenho do sistema está aquém do crescimento desejado pela empresa, portanto indicadores como custo de mão de obra e custo de investimento, por exemplo, poderão ser limitantes para o crescimento.

Palavras-chave: Sistemas produto-serviço (PSS). Sustentabilidade. Desempenho. Serviço de refeições coletivas. 


\begin{abstract}
The product-service system (PSS) is an integrated product and service offering that delivers value and has the potential to lead to sustainable consumption of resources, focusing on reducing material flows in production and also on creating products and services that offer the same level of performance through alternative product use scenarios, increased overall resource productivity, and dematerialization. The food sector portrays this complexity as it is composed of several different stages such as production, processing, transportation and storage until the use-consumption phase offering challenges in the environmental, economic and social spheres, since the PSS represents a family of business model with a focus on sustainability, designed to meet social needs in an economically and environmentally sustainable way. The objective of the research was to analyze the sustainability indicators from the operational and strategic scenarios of a product-service system of a collective meal company. For this, a simulation model was constructed able to portray the performance of the system scenarios and to support the evaluation of the indicators. As a result, it was understood that the performance of the system is below the growth desired by the company, so indicators such as labor cost and investment cost, for example, could be limiting for growth.
\end{abstract}

Key words: Product-service systems (PSS). Sustainability. Performance. Catering service. 


\section{LISTA DE ILUSTRAÇÕES}

Figura 1 - Estrutura conceitual. Adaptado e traduzido de Annarelli et al (2016)..........11 Figura 2 - Esquema do ciclo de vida da solução baseada em parcerias. Traduzido e

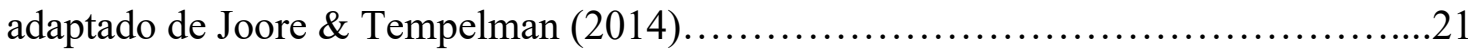
Figura 3 - Exemplo de avaliação ambiental entre duas soluções (S1 e S2). Traduzido e adaptado de Partidário (2004).

Figura 4 - Exemplo de avaliação social entre duas soluções (S1 e S2). Traduzido e

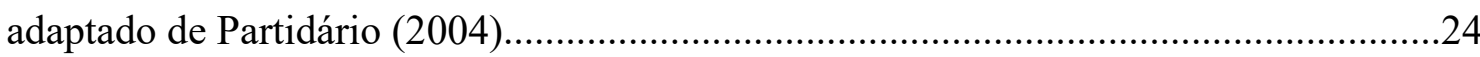

Quadro 1 - Quantidade de trabalhos pesquisados.....................................................25

Figura 5 - Modelo de pesquisa de Vogtlander et al (2002)..........................................30

Figura 6 - Modelo de pesquisa de Linke et al (2013)....................................................

Figura 7 - Modelo de pesquisa de Rondini et al (2017).................................................31

Figura 8 - Modelo de pesquisa de Amrina e Vilsi (2015).............................................32

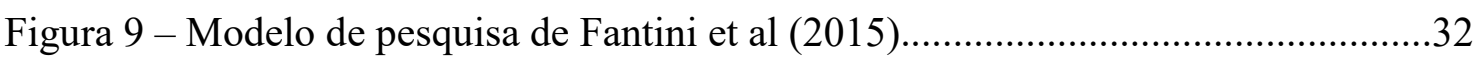

Figura 10 - Modelo de pesquisa de Lee et al (2012) ...................................................33

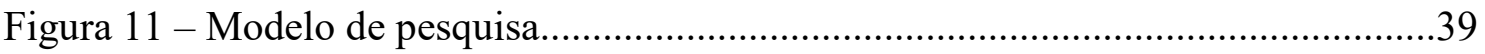

Figura 12 - Classificação dos insumos adquiridos pela empresa X...............................43

Figura 13 - Operação da divisão Delivery da empresa X...............................................44

Figura 14 - Operação da divisão In Company da empresa X........................................45

Figura 15 - Operação dos processos PMV e CC realizadas na matriz............................46

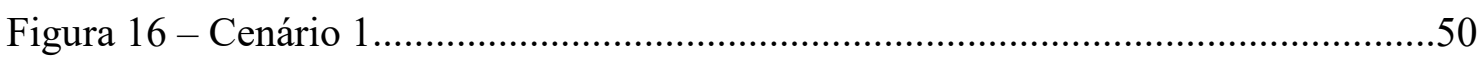

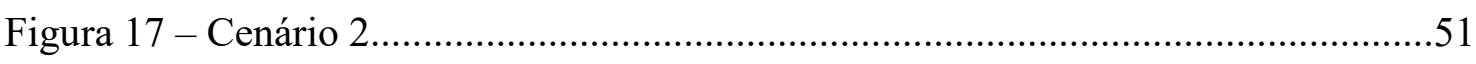

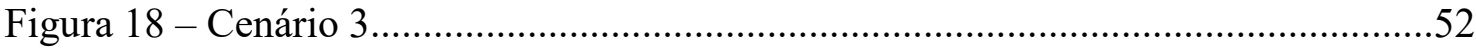

Figura 19 - Estrutura de simulação construída no ProModel ilustrando o cenário 1......53

Figura 20 - Estrutura de simulação construída no ProModel ilustrando o cenário 2 ......53

Figura 21 - Estrutura de simulação construída no ProModel ilustrando o cenário 3......54 


\section{LISTA DE TABELAS}

Tabela 1 - Indicadores de sustentabilidade relacionados ao desempenho do sistema...25

Tabela 2 - Quadro resumo das etapas dos procedimentos de pesquisa..........................41

Tabela 3 - Lista de indicadores não selecionados.......................................................48

Tabela 4 - Lista de indicadores de desempenho da sustentabilidade............................49

Tabela 5 - Resultado da simulação antes da alteração do cenário 3 ...............................55

Tabela 6 - Resultado da simulação considerando novos dados para o cenário 3...........55

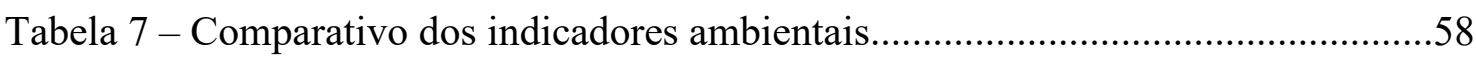

Tabela 8 - Comparativo dos indicadores econômicos..................................................59

Tabela 9 - Comparativo dos indicadores sociais....................................................60 
LISTA DE ABREVIATURAS

PSS Sistema Produto-Serviço

ICT Informação e Tecnologia de Comunicação

UNEP United Nations Environment Programme

KPI Indicador de Desempenho Chave

OECD Organisation for Economic Co-operation and Development

ISSO International Organization for Standardization

GRI Global Reporting Initiative

TBL Triple Bottom Line

DES Simulação de Eventos Discretos

ABM Modelagem de Agentes Base

SD Sistemas Dinâmicos

DEMS Modelagem e Simulação de Eventos Discretos

PIB Produto Interno Bruto

ABERC Associação Brasileira das Empresas de Refeições Coletivas

ABIA Associação Brasileira das Indústrias da Alimentação

VMP Vegetais Minimamente Processados

PMV Processamento Mínimo de Vegetais

CC Cook \& Chill 
1 INTRODUÇÃO

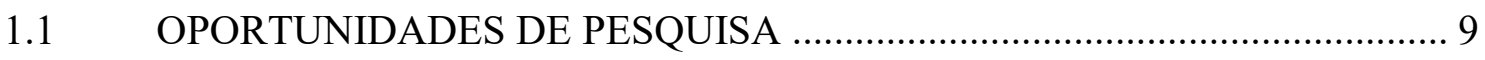

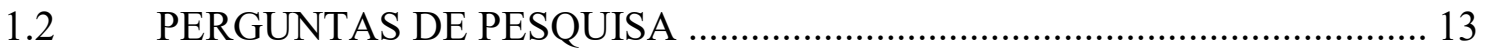

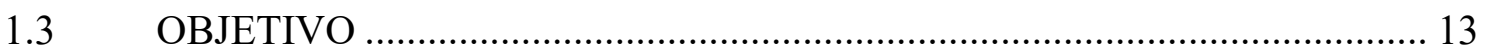

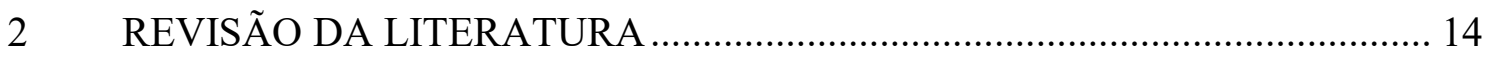

2.1 SISTEMAS PRODUTO-SERVIÇO (PSS) …………………….............. 14

2.2 SUSTENTABILIDADE NO PSS ........................................................... 18

2.2.1 DIMENSÃO ECONÔMICA ……………………………………....... 21

2.2.2 DIMENSÃO AMBIENTAL.......................................................... 22

2.2.3 DIMENSÃO SOCIAL..................................................................... 23

2.3 INDICADORES DE DESEMPENHO DA SUSTENTABILIDADE NO PSS .. 24

2.3.1 SIMULAÇÃO COMO FERRAMENTA DE ANÁLISE ...................................... 33

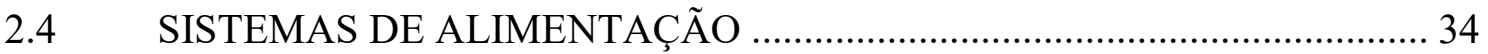

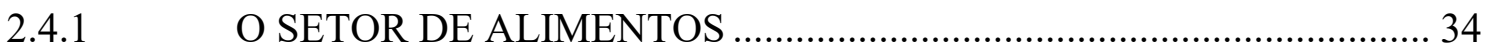

2.4.2 SERVIÇOS DE ALIMENTAÇÃO/REFEIÇÕES COLETIVAS ............. 35

2.4.3 PROCESSAMENTO MINIMO DE VEGETAIS ……………………...... 36

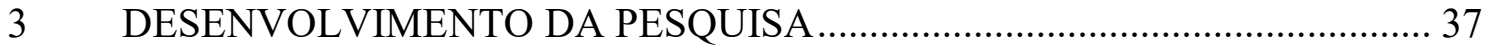

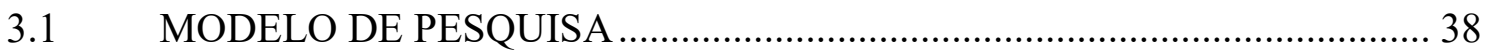

3.3 PROCEDIMENTOS DA PESQUISA …………….................................... 41

3.3.1 UNIDADE DE ANÁLISE................................................................. 42

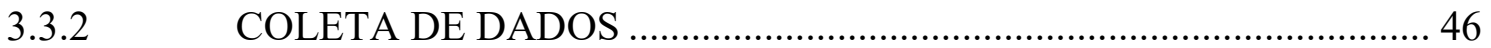

3.3.3 VALIDAÇÃO DOS CENÁRIOS DE SIMULAÇÃO ………………….... 48

$4 \quad$ RESULTADOS E DISCUSSÕES ............................................................... 52

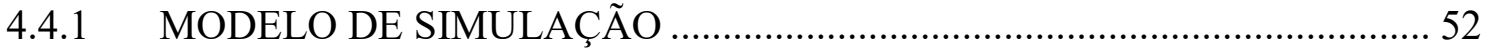

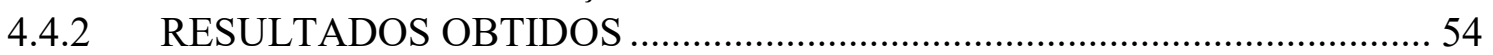

4.4.3 COMPARATIVO DOS CENÁRIOS ……………………………………….... 55

4.4.4 ANÁLISE DOS INDICADORES E DESEMPENHO DO SISTEMA ............. 57

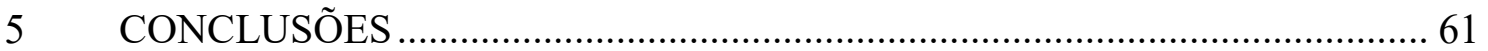

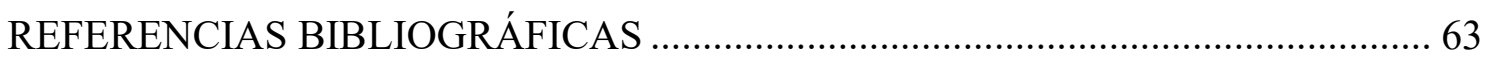

ANEXO A - TELA DE PARÂMETROS DE SIMULAÇÃO DO CENÁRIO 1 NO

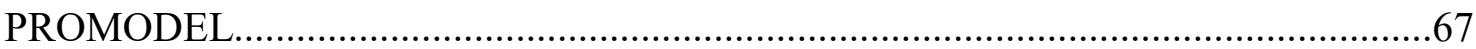

ANEXO B - TELA DE PARÂMETROS DE SIMULAÇÃO DO CENÁRIO 2 NO

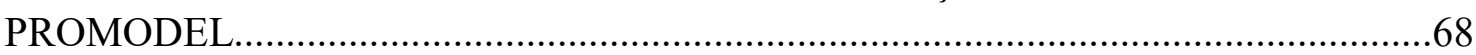

ANEXO C - TELA DE PARÂMETROS DE SIMULAÇÃO DO CENÁRIO 3 NO

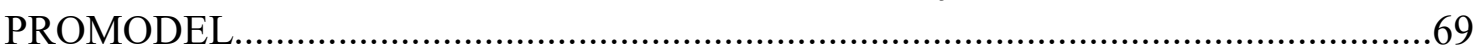


O PSS tem potencial de conduzir ao consumo sustentável de recursos, visando uma efetiva transformação do comportamento sociocultural, com envolvimento da comunidade (XING; WANG; QIAN, 2013) e mudança nos padrões de utilização (MONT, 2004; CESCHIN, 2013; SANTAMARIA; ESCOBAR-TELLO; ROSS, 2016) e, em uma perspectiva mais ampla, impactando na sociologia de consumo (MYLAN 2015), contribuindo para a transição de uma sociedade de descarte para uma sociedade de recuperação (COOK, 2014), rumo a uma economia circular (TUKKER, 2015).

O PSS representa uma família de modelo de negócio com foco na sustentabilidade (MAXWELL; VAN DER VORST, 2003; MAXWELL; SHEATE; VAN DER VORST, 2006; VASANTHA; ROY; CORNEY, 2016), destinados a satisfazer as necessidades sociais de uma forma economica e ambientalmente sustentável (HANNON; FOXON; GALE, 2015).

Assim, o PSS deveria objetivar a redução do impacto ambiental proveniente do consumo, pelo fechamento do ciclo dos materiais e por meio de cenários alternativos de uso do produto, o aumento da produtividade global de recursos, e a desmaterialização (MONT, 2002). O PSS desvincula a ideia de valor à quantidade de material físico (VEZZOLI; CHESCHIN; DIEHL, 2015), focando na redução dos fluxos de materiais na produção e no consumo e também na criação de produtos e serviços que ofereçam aos clientes o mesmo nível de desempenho, porém, com uma carga ambiental menor (LEE et al., 2012).

\section{$1.1 \quad$ OPORTUNIDADES DE PESQUISA}

$\mathrm{Na}$ revisão sistêmica da literatura de Qu et al (2016), os autores estudaram metodologias de avaliação do PSS na perspectiva do valor para o cliente e da sustentabilidade, bem como os trade-offs entre elas. Os autores relataram que embora o PSS seja defendido devido às suas vantagens na proteção ambiental, as pesquisas ainda são bastante limitadas quanto à sustentabilidade. Além disso, as pesquisas prestam pouca atenção às perspectivas de produção e custo, que também são cruciais no processo de avaliação e operação do PSS, gerando a necessidade de mais critérios para avaliar a eficiência de um PSS. 
Baines et al (2007) relataram que mesmo existindo uma gama de ferramentas e metodologias no desenho do PSS presentes na literatura, ainda há uma grande lacuna na avaliação crítica e aprofundada da performance dessas ferramentas na prática, e ainda propõem a utilização de mais métodos quantitativos em trabalhos futuros. Para Wang et al (2011) são necessários o desenvolvimento de ferramentas que permitam modelar e avaliar o nível de serviço, os benefícios econômicos e ambientais do PSS e o valor dos potenciais clientes. As análises ambientais empregam principalmente metodologias qualitativas e descritivas, ou seja, há poucas metodologias quantitativas capazes de descrever e avaliar também os efeitos indiretos na dimensão social e ambiental atribuíveis ao PSS (ANNARELLI et al, 2016).

Beuren et al (2013) sugeriram pesquisas no desenvolvimento de ferramentas e metodologias que possam satisfazer os requisitos do PSS, e que mesmo existindo uma gama de ferramentas e metodologias para a concepção do PSS, ainda é necessária uma avaliação do funcionamento destas ferramentas na prática considerando todo o sistema, adaptando-se a diferentes cenários que satisfaçam a demanda das partes interessadas.

Reim et al (2014) sugeriram mais estudos quantitativos para se entender a influência de um modelo de negócio sobre a performance da empresa.

$\mathrm{Qu}$ et al (2016) relataram que mais pesquisas quantitativas precisam ser conduzidas, porque além de serem mais objetivas e persuasivas, demonstram a influência do PSS sobre a economia, a sociedade e o meio ambiente. Rondini et al (2017) acharam interessante o desenvolvimento de cenários do PSS para avaliação de melhorias utilizando a ferramenta de simulação como base.

A revisão de Annarelli et al (2016) destacou que há um número muito baixo de documentos que fornecem uma análise capaz de cobrir todos os três aspectos da sustentabilidade, e que seguindo a metodologia proposta em 1999 por Goedkoop et al, existe uma clara necessidade de novas análises inovadoras que abranjam os três aspectos do potencial de sustentabilidade do PSS. Mourtzis et al (2015) também citaram a existência de métodos limitados que se concentram em medir simultaneamente os três componentes de sustentabilidade (econômico, ambiental e social).

Annarelli et al (2016) categorizaram a literatura ligada ao PSS em 4 grupos de enfoque (Econômico, Ambiental, Projeto/Design e Global) com seus respectivos focos de pesquisa (Sustentabilidade, Estratégia, Informação e tecnologia de comunicação (ICT), Produção, Design e Logística/Redes) como ilustra a figura 1. A estrutura conceitual de Annarelli et al (2016) abrange os principais trabalhos realizados em PSS 
desde 1988 até 2016, totalizando 224 artigos cobrindo as áreas de negócios e gestão, engenharia, ciências da decisão e do ambiente, economia e finanças, sendo a maioria publicações do periódico "Journal of Cleaner Production".

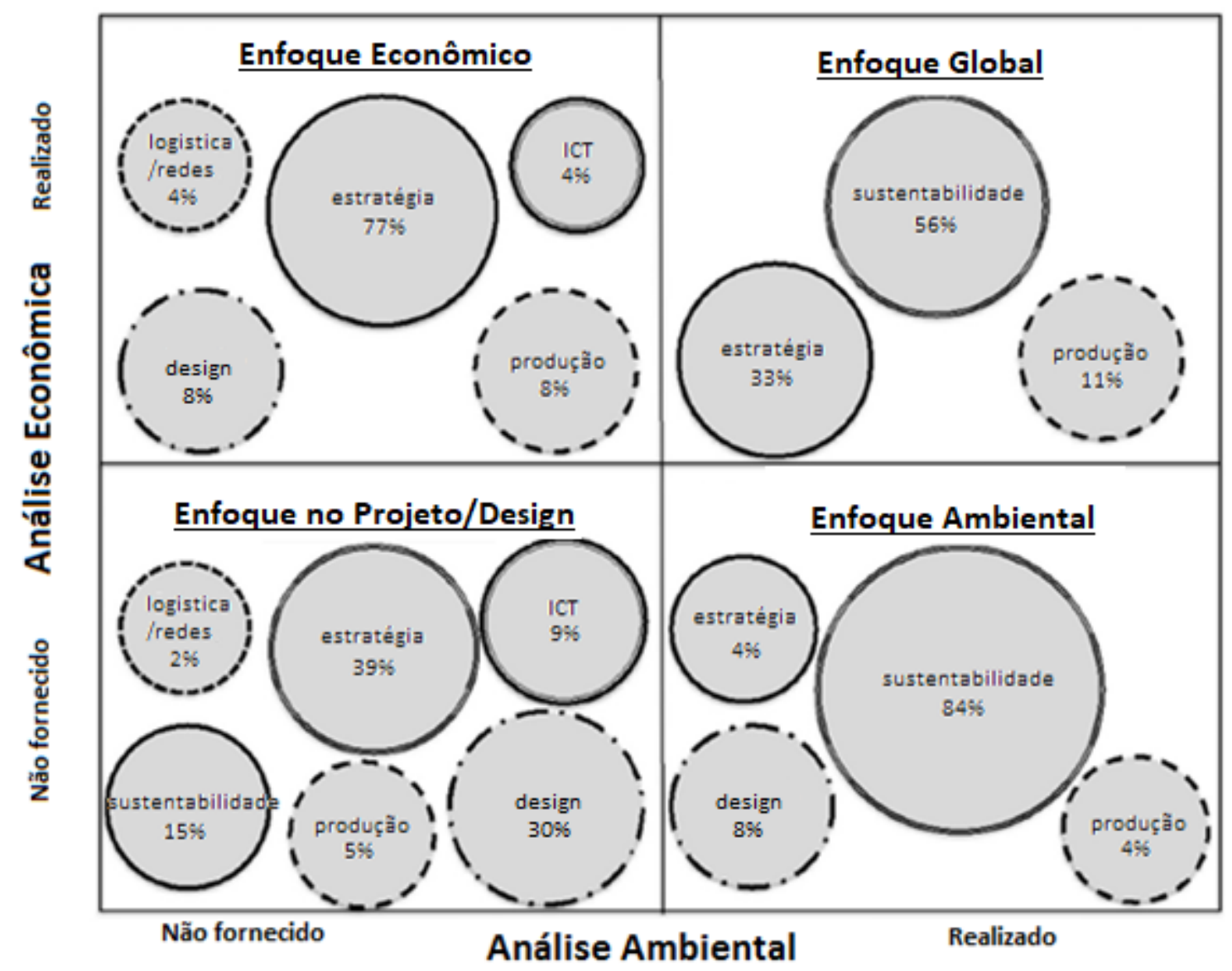

Figura 1: Estrutura conceitual. Adaptado e traduzido de Annarelli et al (2016).

O grupo de Enfoque Econômico são pesquisas que fornecem uma análise do potencial econômico do PSS, principalmente em termos quantitativos. O grupo de Enfoque Ambiental trata da análise ambiental e social do PSS, principalmente em termos de aplicações no PSS e seus impactos. O Enfoque de Projeto/Design são pesquisas voltadas ao desenho/desenvolvimento do PSS objetivando prover guias, ferramentas e metodologias no processo de desenho do PSS. Por fim, as pesquisas do grupo de Enfoque Global conciliam tanto a análise econômica como a ambiental em um mesmo trabalho de pesquisa.

Os focos de pesquisa são compilados dos principais temas relacionados ao PSS. A sustentabilidade surgiu como um dos principais tópicos e se faz presente até os dias de hoje nas pesquisas, abordando temas como reuso, reciclagem, ciclo de vida do produto, 
compartilhamento, redução do consumo, entre outras abordagens. O foco em estratégia vem ganhando espaço e ocupa o maior volume de artigos, englobando temas como modelos de negócio orientados a produto, uso ou resultado. O foco em design está relacionado a métodos de desenho do PSS, inovação de produtos e a satisfação do cliente. Em menor volume os focos em produção, ICT e redes/logística, tratam respectivamente de manufatura/remanufatura, sistemas de informação/novas tecnologias, e cadeia de suprimentos/engajamento de fornecedores.

Os autores propuseram pesquisas futuras focadas na integração dos três aspectos da sustentabilidade (econômicos, sociais e ambientais) no processo de desenho do PSS. Eles enfatizaram o baixo número de artigos os quais abranjam esses três aspectos assim como fizeram Goedkoop et al em 1999. Evans et al (2007) também abordaram os três aspectos da sustentabilidade com enfoque no fabricante de uma rede de parceiros em um sistema de produção alimentícia.

Evans et al (2007) consideraram soluções no setor de alimentos porque são sistemas complexos que compõem vários atores e diferentes fases: produção, processamento, transporte, armazenamento, etc., antes da fase de uso-consumo. Os autores reforçam que esse setor oferece desafios de inovação particularmente interessantes, pois o PSS deve se adaptar a várias necessidades do consumidor.

Diante do cenário abordado, justifica-se o estudo da avaliação do PSS o qual relacione de forma integrada aspectos econômicos, ambientais e sociais de um modelo de negócio. Além das oportunidades relatadas, a estrutura proposta por Annarelli et al (2016) (Figura 1) consolida a importância do tema sustentabilidade em uma análise de enfoque global, representando $56 \%$ das pesquisas, dando assim relevância ao tema.

De forma complementar, o foco em produção representa apenas $11 \%$ das pesquisas, demonstrando que poucos trabalhos trataram a manufatura como tema central, abrindo oportunidades de se estudar o PSS nessa área de aplicação. A maioria dos autores citados até o momento reforçaram a necessidade de se utilizar análises e ferramentas quantitativas, agregando assim relevância para se explorar cenários de análise de desempenho de um sistema produto-serviço.

Assim, este trabalho tem o foco no estudo de um sistema PSS de uma empresa de refeições coletivas e seu desempenho em termos das dimensões da sustentabilidade econômica, ambiental e social. 


\subsection{PERGUNTAS DE PESQUISA}

Diante do exposto na seção anterior, pode-se questionar como se daria a integração dos aspectos econômico, ambiental e social da sustentabilidade na medição do desempenho de um sistema produto-serviço, e também como diferentes elementos ou configurações da manufatura poderiam ser avaliados pela ótica integrada da sustentabilidade. Assim, pode-se apresentar algumas perguntas de pesquisa para este trabalho:

- A simulação como método quantitativo é capaz de contribuir na avaliação do desempenho de um PSS de uma empresa de refeições coletivas?

- Como avaliar o desempenho de um sistema produto-serviço por meio da avaliação dos indicadores da sustentabilidade?

- Como é a relação entre a manufatura de uma empresa de refeições coletivas e os indicadores da sustentabilidade?

\subsection{OBJETIVO}

O objetivo da pesquisa foi avaliar o desempenho do sistema através da análise dos indicadores da sustentabilidade. Para isso, construiu-se um modelo de simulação capaz de retratar os cenários operacionais de um sistema produto-serviço de uma empresa de refeições coletivas.

Para realizar esse objetivo, primeiramente foi concebido um modelo para avaliação do desempenho que integrou o PSS e as dimensões da sustentabilidade. Em seguida, foi realizada uma pesquisa de campo em uma empresa de refeições coletivas que está fazendo mudanças na manufatura, e as situações anteriores, atual e futura foram consideradas cenários e avaliadas por meio do modelo concebido pelo método da simulação. Na mesma pesquisa de campo, selecionou-se alguns indicadores da sustentabilidade que iriam compor a discussão dos resultados.

Por fim, com os resultados da simulação e dos indicadores da empresa, fez-se uma discussão sobre a relação entre eles de acordo com cada cenário operacional da empresa. 


\subsection{SISTEMAS PRODUTO-SERVIÇO (PSS)}

Uma possível definição é que "Um Sistema Produto-Serviço (PSS) é um conjunto comercializável de produtos e serviços capazes de satisfazer conjuntamente a necessidade de um usuário. O PSS é fornecido por uma única empresa ou por uma aliança de empresas. Ele pode incluir produtos (ou apenas um) mais serviços adicionais. Pode incluir um serviço mais um produto adicional e, também, produto e serviço, juntos, podem ser igualmente importantes para a realização da função" (GOEDKOOP, 1999).

De acordo com Baines et al (2007), PSS é uma oferta de produto e serviço integrados que entregam valor em uso e tem como premissa aumentar este valor à medida que se reduz custos no sistema.

Para Mont (2002), um PSS deve ser definido como um sistema de produtos, serviços, redes de apoio e infraestrutura que é projetado para ser competitivo, satisfazer as necessidades do cliente e ter um impacto ambiental menor do que os modelos de negócios tradicionais.

O conceito de PSS, que emergiu com um de seus propósitos promover a produção e a utilização/operação sustentável, pode ser considerado como uma estratégia competitiva para satisfazer diversos requisitos dos clientes, bem como dos fabricantes (GENG et al, 2011). Algumas empresas estão empregando elementos de PSSs como uma extensão natural de suas ofertas existentes para os clientes (MONT, 2002).

A lógica do PSS se baseia na estratégia de desenvolvimento de valor das empresas de manufatura, sendo que com o tempo os valores orientados ao produto passaram a serem orientados ao serviço (WANG et al, 2011). Embora muitos especialistas tenham opiniões diferentes, muitos autores (GOEDKOOP, 1999; MONT, 2002; MANZINI, VEZZOLI, 2003; TUKKER, 2004; MORELLI, 2006; BAINES et al, 2007; DORUGBO et al, 2010; BORCHARDT et al, 2010; WANG et al, 2011; BOEHM, THOMAS, 2013), de acordo com a revisão sistemática da literatura de Annarelli et al (2016), tratam o PSS como um modelo de negócio, e neste caso temos as seguintes classificações propostas por Tukker (2004) e Baines et al (2007):

Orientado a produto - $\mathrm{O}$ foco é a venda do produto com alguns serviços opcionais. Os fabricantes fornecem produtos e serviços relacionados aos consumidores que possuem a propriedade do produto. Os serviços incluem manutenção, reparo, distribuição, 
reutilização, reciclagem e ajuda aos clientes a otimizar a aplicação de um produto através de treinamento e consultoria. Nesse caso, o produto é considerado como um meio para entregar serviços.

Orientado ao uso - O produto continua tendo um papel central, porém não está voltado para a venda dele, continuando em propriedade do provedor. Os fabricantes que possuem a propriedade de produtos oferecem aos clientes o uso e a função dos produtos. Exemplos típicos do PSS orientado para o uso são o aluguel, arrendamento ou compartilhamento de produtos.

Orientado a resultado - Cliente e fornecedor entram em acordo por um resultado sem a necessidade de um produto envolvido. O fabricante oferece uma mistura personalizada de serviços para garantir um determinado resultado e os clientes pagam apenas pelo resultado.

Como resultado desses modelos, as empresas se tornam provedores de soluções, não apenas fornecedores de produtos, e os consumidores pagam por uso, e não por produto. Assim, o centro de lucro para os produtores não vem de vender mais e mais produtos, mas de novas áreas de criação de valor em manutenção, atualização, uso e serviços de fim de vida (MONT, 2004).

Tukker (2004) retrata que atividades de terceirização da gestão são consideradas orientadas a resultado, porque os acordos contratuais estabelecidos entre contratado e contratante se baseiam na entrega de resultados como indicadores. Um exemplo típico relatado é a indústria de catering/food service que são responsáveis pela produção e distribuição da refeição bem como o serviço de atendimento. Os contratos de serviços estabelecidos reduzem a variabilidade e a imprevisibilidade da demanda em relação à capacidade instalada e permitem uma maior utilização da capacidade média (OLIVA; KALLENBERG, 2003). Baines et al (2007) apontam que os modelos orientados a resultado são mais sofisticados e representam a maior parte das características do PSS.

No entanto, nos modelos empresariais orientados para o resultado, o uso de materiais é apenas um fator de custo dos produtos, não levando ao aumento das receitas. Eles visam reduzir a intensidade do material dos sistemas existentes, assumindo a responsabilidade de fornecer, manter, recuperar e reciclar todos os aspectos físicos do sistema (ROY, 2000).

Os modelos de negócio orientados a resultado são considerados também como orientados a solução, sendo assim devem adaptar o serviço de acordo com as necessidades 
do cliente (REIM et al, 2014), por exemplo o mercado têxtil infantil, o qual fornece pacotes de roupas de acordo com o tamanho do bebê, fazendo a substituição delas conforme a criança cresce, juntamente com um serviço de lavagem para posterior reutilização por outros clientes (CORVELLEC; STAL, 2017). Por isso, em princípio, além de reduzir os custos dos materiais, usando menos, há um incentivo em usá-los por mais tempo (TUKKER, 2015).

$\mathrm{Na}$ visão da sustentabilidade, esse tipo de modelo incentiva os produtores a serem criativos em seus modos de operar e com isso obter uma melhor utilização de recursos (REIM et al, 2015).

De acordo com Mont (2002), o PSS tem potencial de reduzir o número de produtos pela oferta de serviços e cenários alternativos como exemplos a locação, compartilhamento e comodato, tornando os produtores mais responsáveis pelos seus produtos, bem como o ciclo de vida deles. Há uma ampla gama de benefícios de um PSS; para o produtor significa uma oferta de maior valor que é mais facilmente diferenciada, para o cliente é uma libertação das responsabilidades de propriedade de ativos e para a sociedade em geral uma abordagem mais sustentável para negócios (BAINES et al, 2007).

Para a realização completa do PSS, a colaboração entre as partes interessadas nos ciclos de vida do produto é necessária. Entre os três principais interessados (por exemplo, usuários, governos e fabricantes), os fabricantes são cruciais como decisores ativos para selecionar e realizar uma aplicação PSS entre alternativas de design potencial, enquanto os usuários e o governo restringem possíveis PSSs por meio da especificação de requisitos de função e legislação (KOMOTO et al, 2005).

Para Mont (2002) os produtores têm um papel fundamental no desenvolvimento de um PSS. Os fabricantes e prestadores de serviços se responsabilizam em todas as fases do ciclo de vida, por exemplo a organização adequada dos sistemas de retirada para reutilização, remanufatura e reciclagem com o intuito de educar os consumidores sobre o uso eficiente do produto. Para Komoto et al (2005), os fabricantes têm como principal preocupação a adaptação do conceito PSS ao ciclo específico de vida do produto. O PSS deve ser projetado em uma fase inicial e atualizado em todas as fases do ciclo de vida do produto.

Compreender os PSSs oferece a oportunidade de ver novas estratégias, tendências e desenvolvimentos do mercado, bem como a transformação dos padrões de produção e consumo orientados pelos fatores ambientais (MONT, 2002). 
O PSS tem a capacidade de absorver materiais do ambiente e transformar em produtos. E no fim, todos os produtos são transformados em algum tipo de refugo e devolvidos ao ambiente (CORVELLEC; STAL, 2017).

Evans et al (2007) definem um sistema como uma entidade coletiva que visa alcançar um objetivo, consistindo em um arranjo de elementos materiais e imateriais (componentes, partes e subsistemas). Esses elementos são inter-relacionados, interdependentes ou interagidos (por exemplo, produtos, serviços, regras de operação, procedimentos e organizações). Para um PSS, os elementos se combinam para permitir que o usuário atinja uma certa necessidade.

Ao considerar o sistema produto-serviço como sendo feito de elementos múltiplos, potencialmente entregues por diferentes atores e integrados através de uma arquitetura de plataforma, pode ser possível criar um PSS de alto desempenho (EVANS et al, 2007).

Dessa forma o PSS seria, simultaneamente, econômico (ao permitir a industrialização e a produção em maior volume de alguns dos elementos PSS), de baixo impacto ambiental (através de cada ator em um acordo de parceria que crie interesse próprio ao longo do ciclo de vida do sistema e através de uma arquitetura de plataforma que permita que alguns elementos físicos do sistema sejam entregues localmente) e mais próximo da necessidade do cliente (através de uma arquitetura que encoraje a personalização para necessidades individuais) (EVANS et al, 2007).

Dentre outras vantagens do PSS são que os produtores poderiam diferenciar seus produtos com um elemento de serviço personalizado que não seria fácil de copiar; criar soluções integradas em vez de um único produto; melhorar a satisfação do cliente e aumentar a fidelidade do cliente; receber serviços personalizados e integrados de fornecedores, e assim se concentrar mais em seu core business (WANG et al, 2011).

A importância do pensamento do ciclo de vida no ambiente empresarial está aumentando. As cadeias de suprimentos são muito complexas para serem facilmente gerenciadas. Há sinais de que o processo está se movendo lentamente para desencadear ações na cadeia ao longo do ciclo de vida do produto. Entretanto, ainda são poucas as iniciativas tomadas pelos produtores para abordar as questões ambientais das fases do ciclo de vida (MONT, 2004).

Para Durugbo et al (2010) há muitos benefícios potenciais que o PSS pode oferecer, os quais podem ser impulsionados pela orientação de uma indústria para redução de carga ambiental, melhorando a eficiência em processos. 
O desenvolvimento do PSS, visto como um todo, apresenta um potencial para gerar soluções vantajosas para o lucro que promovam lucros, benefícios ambientais e sociais. Eles têm o potencial de fornecer as condições necessárias, se não suficientes, para permitir que as comunidades tenham padrões econômicos com menor uso de recurso (MANZINI; VEZZOLI, 2002).

O PSS incorpora o potencial de ideias inovadoras sustentáveis para empresas em diferentes contextos socioeconômicos, pois vinculam a sustentabilidade com as dinâmicas existentes e emergentes de mudanças econômicas e culturais. O PSS tem potencial para abrir novos mercados (MANZINI; VEZZOLI, 2002).

\subsection{SUSTENTABILIDADE NO PSS}

A partir de meados da década de 90, o PSS tornou-se um assunto popular para pesquisadores envolvidos com a sustentabilidade e negócios. Os pesquisadores de sustentabilidade argumentaram que, se alguém se concentrasse nas necessidades dos usuários finais ou no serviço, ao invés do produto, tornaria muito mais fácil projetar sistemas de atendimento de necessidades com impactos radicalmente mais baixos (TUKKER, 2015).

Tukker (2004) explica que a sustentabilidade se trata do uso mínimo de recursos e emissões. Para o sucesso de um negócio, alguns elementos chave são importantes na geração de valor ao PSS como os custos de produção (TUKKER, 2004). A sustentabilidade é uma das características mais importantes do PSS na combinação de produtos e serviços (QU et al, 2016).

O fluxo reduzido de recursos também requer uma cooperação mais forte com os fornecedores. Os benefícios econômicos e de informação da fase de fornecimento de serviços (etapa do consumidor) podem ser facilmente transferidos para o estágio de fabricação, desenvolvimento/design, de modo que todo o sistema se torna mais sensível aos parâmetros de mercado em mudança e é provavelmente mais propensos a estimular a inovação (MONT, 2002). Tonelli et al (2013) citam o trabalho de Evans et al (2007) como direcionador de práticas de desmaterialização dos serviços e melhoria na eficiência dos produtos manufaturados.

Goedkoop et al (1999) analisaram o caso de uma empresa que utiliza um sistema de subscrição para o fornecimento de vegetais orgânicos. O serviço prestado utilizava menos embalagens, pois os produtos eram armazenados em caixas reutilizáveis, sacos de 
papel ou bolsas para compras para uso doméstico. Os benefícios encontrados na pesquisa foram a redução de resíduos de embalagens, tanto na fase de transporte como no envase do produto final. Como todos os produtos são cultivados organicamente, não houve uso de pesticidas, nem fertilizantes artificiais e, portanto, o impacto no solo é diminuído. Os autores relataram que desde a introdução do serviço, as lojas de alimentos orgânicos experimentaram um crescimento adicional de $15 \%$, alcançando um crescimento de receita de 50\% no ano de 1998 (GOEDKOOP et al 1999).

A sustentabilidade é a capacidade de preservar, suportar e nutrir. Significa identificar, desenvolver e promover estruturas mentais, práticas e políticas sustentáveis, a fim de manter um ambiente natural saudável, mas de maneira economicamente sólida e socialmente viável (MOON, 2016).

Segundo Manzini e Vezzoli (2002) em um trabalho publicado na UNEP (United Nations Environment Programme), a eco eficiência potencial de um PSS depende da otimização do sistema (em uso e emissões de recursos) devido à convergência de interesses dos stakeholders. Por outro lado, a adoção de um modelo de negócios PSS implica novos tipos de relacionamentos e/ou parcerias das partes interessadas, nova convergência de interesses econômicos e uma otimização de recursos sistêmicos concomitantes. Por exemplo, um maior nível de especialização e de características tecnológicas que um fornecedor pode economizar e otimizar o consumo de recursos e a produção de resíduos podem, em conjunto, levar a maiores eco eficiências para uma empresa.

As empresas estão se preparando por meio da redução de recursos e energia durante o processo produtivo e do redesenho do sistema industrial e dos modelos de negócio de modo a adicionar o mesmo valor com uma redução de $25 \%$ nos materiais de entrada e energia (TONELLI et al, 2013). Como exemplo de recurso, Arcese et al (2015) reforçam a necessidade de esforços voltados à economia de água no setor de alimentos.

Thyberg e Tonjes (2016) relataram que diante da demanda de alimentos locais e sazonais, para frutas e vegetais importados e não sazonais, houve um aumento no processamento de alimentos e, consequentemente, um aumento de energia, transporte e materiais de insumos.

Tonelli et al (2013) mencionam que o domínio da sustentabilidade hoje, de fato, difere dos drivers do passado recente, como regulamentos, políticas, filosofia de gestão e ética, clientes preocupados com o meio ambiente, satisfação do cliente, proteção e 
conservação, pois as questões atuais focam em disponibilidade de recursos, cadeia de suprimentos sustentável e fornecimento de energia.

Em pesquisas mais recentes, Cauchick Miguel e Sousa-Zomer (2018) conduziram um estudo de caso do PSS como modelo de negócio sustentável em uma economia emergente para fornecer insights sobre o papel das novas formas de proposição de valor, criação de valor e captura de valor no apoio a tecnologias inovadoras no setor de água e na contribuição para a sustentabilidade.

O trabalho de Evans et al (2007) envolveu uma mudança do antigo sistema de entrega de alimentos para casas individuais em horários especificados para um sistema de pedidos de alimentos on-line que foi mais rápido e ofereceu uma escolha mais ampla. As entregas de comida foram entregues a um mercado e outro local específico onde os consumidores poderiam vir e obter comida e, também, comprar frutas frescas. Esta solução resultou em uma mudança significativa na logística e na redução dos impactos e custos ambientais. Segunda Evans et al (2007), "Isso também levou a um maior nível de satisfação, pois aumentou a vida social dos consumidores e melhorou o estado de sua saúde" (apud DURUGBO et al, 2010).

Para Vasantha et al (2012), os desafios para o desenvolvimento de um PSS sustentável são:

- O PSS deve integrar considerações econômicas, ambientais e sociais em uma abordagem holística, a fim de produzir mudanças radicais e identificar os graus de liberdade de mudança no sistema geral de produção e consumo.

- O PSS deve oferecer oportunidades para que os fabricantes desenvolvam o potencial comercial de um design ambientalmente consciente e diferenciem os seus produtos atendendo às necessidades dos clientes segmentados de maneira sustentável.

Lee et al (2012) definiram a sustentabilidade de um PSS a partir da perspectiva integrada dos aspectos ambiental, econômico e social. Nessa abordagem um PSS ambientalmente sustentável implica numa base de recursos em atividades de produção e consumo mais capazes do que o produto existente. Um PSS economicamente sustentável implica em uma operação que atenda às expectativas dos stakeholders. Já um PSS socialmente sustentável implica em melhorar o bem-estar público.

A sustentabilidade é uma característica crítica no desenho do PSS e permite que as empresas contribuam na redução do fluxo e consumo de materiais (RONDINI et al, 2017). 


\subsubsection{DIMENSÃO ECONÔMICA}

No PSS, tem-se itens de custo adicionais aos quais os fabricantes de produtos estão menos familiarizados. Um exemplo são os custos de transação, uma vez que um PSS geralmente é entregue por um grupo de empresas, resultando em esquemas de contratação e de compartilhamento de receitas mais complicados. E os "produtores de PSS", de repente, assumem maior responsabilidade por entregar um resultado em tempo considerável a um preço pré-acordado (TUKKER, 2015). Empresas orientadas a resultado dependem de bons rendimentos das matérias-primas e dos processos de preparação para garantirem melhores resultados operacionais, justificando assim a importância de um bom critério de performance, afinal o contratante pode levantar questionamentos sobre os resultados entregues pela contratada (TUKKER, 2004).

A figura 2 é um esquema utilizado por Joore \& Tempelman (2004) para introduzir os principais indicadores que fizeram parte da análise econômica de um sistema baseado em parcerias a qual os custos do ciclo de vida estavam focados no transporte e distribuição, nos desperdícios gerados em cada etapa, do material utilizado no processamento e preparação, na energia utilizada para execução da solução e por fim o tempo consumido desde o início até o final do ciclo.

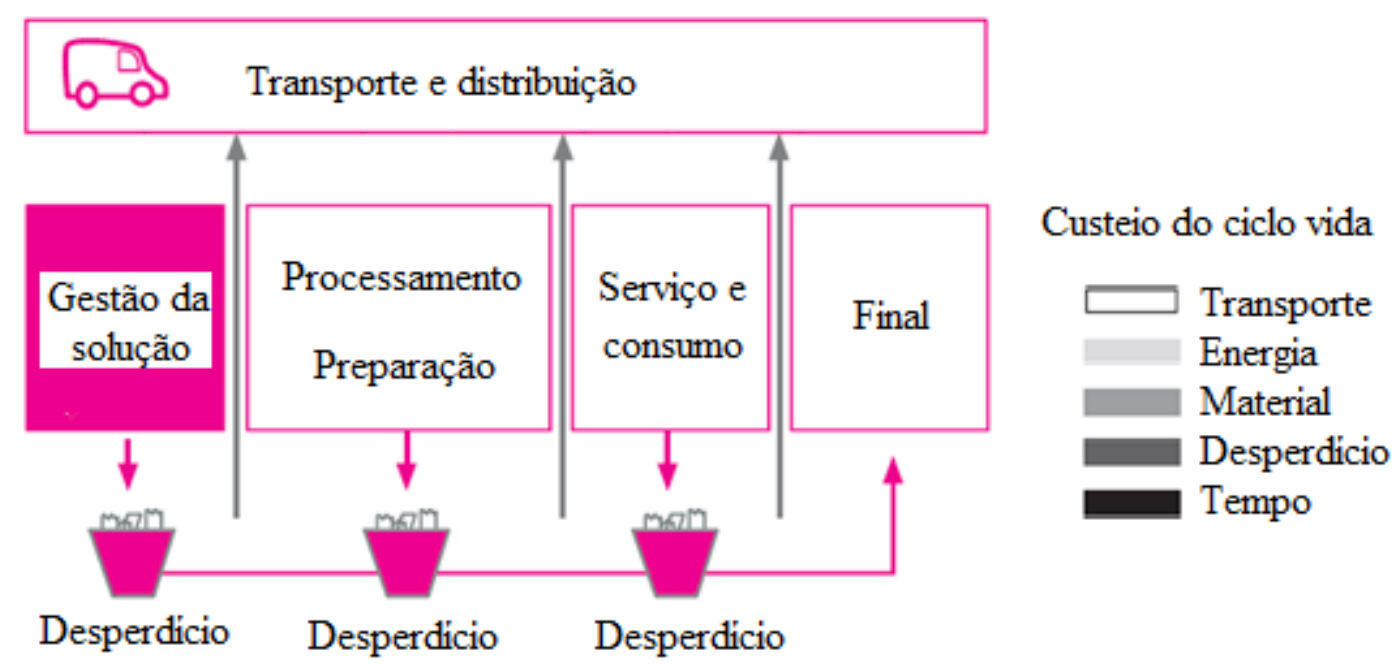

Figura 2: Esquema do ciclo de vida da solução baseada em parcerias (Traduzido e adaptado de Joore \& Tempelman, 2004).

De forma complementar, Manzini (2004) reconhecem que o crescimento econômico também está ligado ao bem-estar da sociedade e à saúde dos ecossistemas. 
Além dos aspectos econômicos, os modelos de negócios do PSS devem enfatizar os aspectos ambientais e sociais (BEUREN et al, 2013).

\subsubsection{DIMENSÃO AMBIENTAL}

Os serviços não são necessariamente menos problemáticos para o meio ambiente do que as indústrias de manufatura, mas em uma economia em que dominam e servem como alguns dos fatores de mudança mais dinâmicos, é importante examiná-los diretamente em busca de oportunidades para travar a degradação ambiental e melhorar a qualidade ambiental. Os PSSs estão focados em abordar a fase de uso para reduzir o peso ambiental total do consumo. No entanto, é necessário considerar cuidadosamente o impacto de outras fases, como atividades de produção e pós-produção (MONT, 2002).

A substituição de energia e materiais por serviços eficientes pode influenciar o consumo geral de recursos. Aumentar a intensidade de uso, se os produtos forem compartilhados ou usados em conjunto, podem potencialmente minimizar o número total de produtos e a capacidade de uso pode ser mais plenamente realizada, resultando em maior eficiência de recursos e menor impacto no meio ambiente (MONT, 2002).

Se a operação do serviço do produto for um custo para a empresa que o internalizou, o produtor pode estar interessado em fornecer manutenção que ajude a prolongar a vida do produto e, assim, reduzir a quantidade do produto necessário para a entrega do serviço que é menos produto por unidade de serviços e, portanto, menor carga ambiental (MONT, 2002).

Para avaliar o desempenho ambiental do PSS, é necessário desenvolver critérios que possam refletir a vida útil de um produto, a eficiência do consumo de recursos, a eficiência do ciclo fechado e o potencial de melhoria (MONT, 2002).

A análise do impacto ambiental de um PSS se inicia pela análise das fases (produção, uso e descarte) do ciclo de vida em que o impacto ambiental dos produtos fisicos é dominante (BORCHARDT et al, 2010).

Como base de critério para avaliar a dimensão ambiental, Evans et al (2007) e Partidário et al (2007) utilizaram o mesmo modelo de avaliação (Figura 3) proposto por Partidário (2004) para avaliar novas soluções nas operações de empresas do ramo alimentício. Os autores identificaram pontos de melhorias na redução do consumo de energia nos processos que envolviam aquecimento durante a preparação dos alimentos e refrigeração na estocagem. Outros pontos importantes envolviam perdas durante o 
processo, aumento de desperdício de água e aumento no uso de embalagens devido ao transporte dos alimentos.

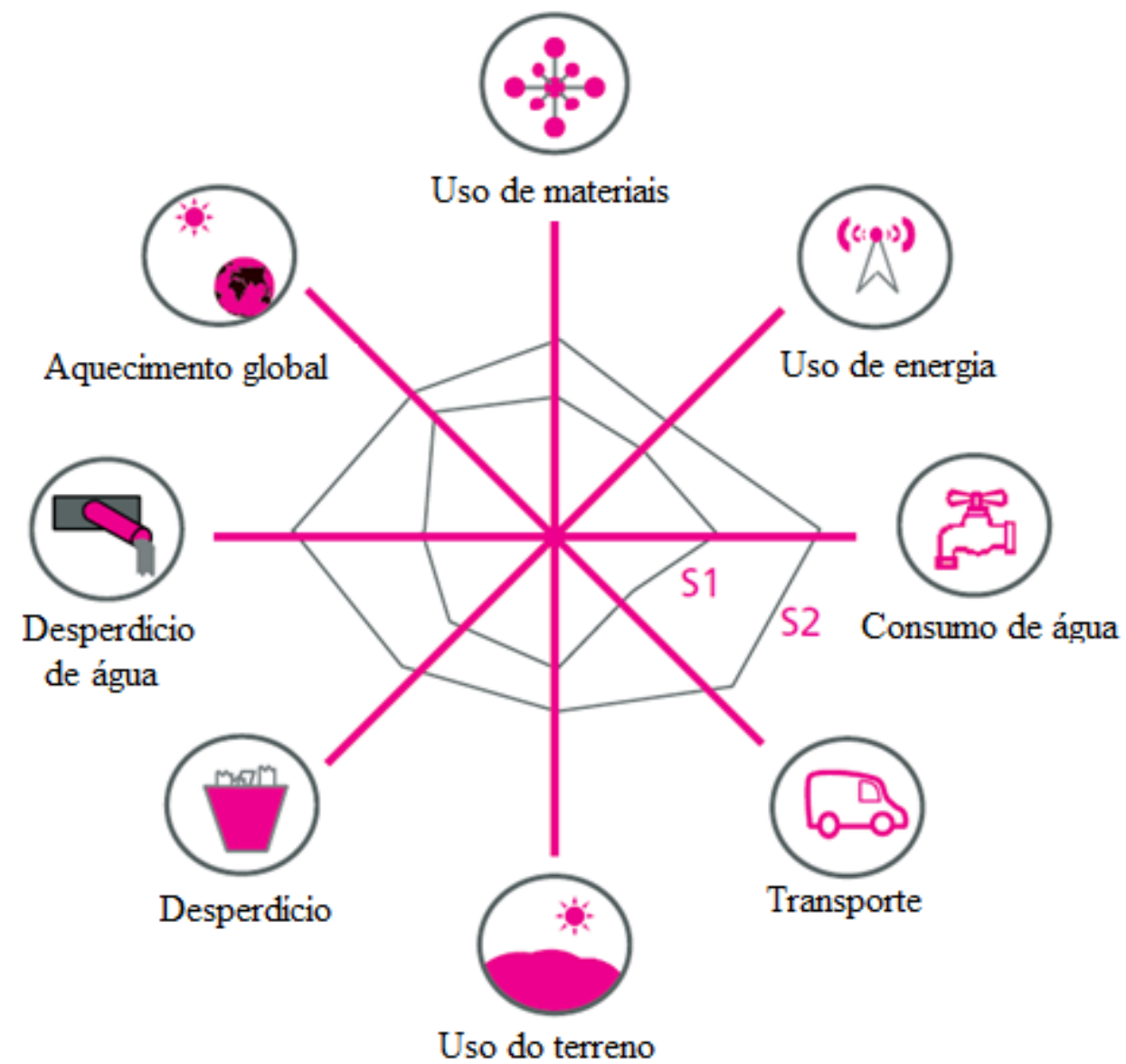

Figura 3: Exemplo de avaliação ambiental entre duas soluções (S1 e S2) (Traduzido e adaptado de Partidário, 2004).

\subsubsection{DIMENSÃO SOCIAL}

A avaliação social é uma avaliação qualitativa e não se destina a fornecer informações quantitativas e estatísticas. Nessa dimensão, avalia-se o valor agregado percebido pelo cliente com a característica de atender às necessidades dele a um custo justo (PARTIDÁRIO, 2004).

Partidário (2004), Evans et al (2007) e Partidário et al (2007) utilizaram o gráfico tipo radar demonstrado na figura 4 para elencar os principais resultados provenientes da comparação de duas soluções sob a ótica social, as quais mostraram os seguintes pontos: a qualidade do produto é muito importante na segurança alimentar, entretanto não é percebido pelo cliente; o timing de resposta de assistência foi positivo na tratativa do 
problema; o acesso e a variedade de escolha proporcionaram conveniência para os clientes; a forma de entrega centralizada proporcionou melhoria no bem-estar e saúde da comunidade local.

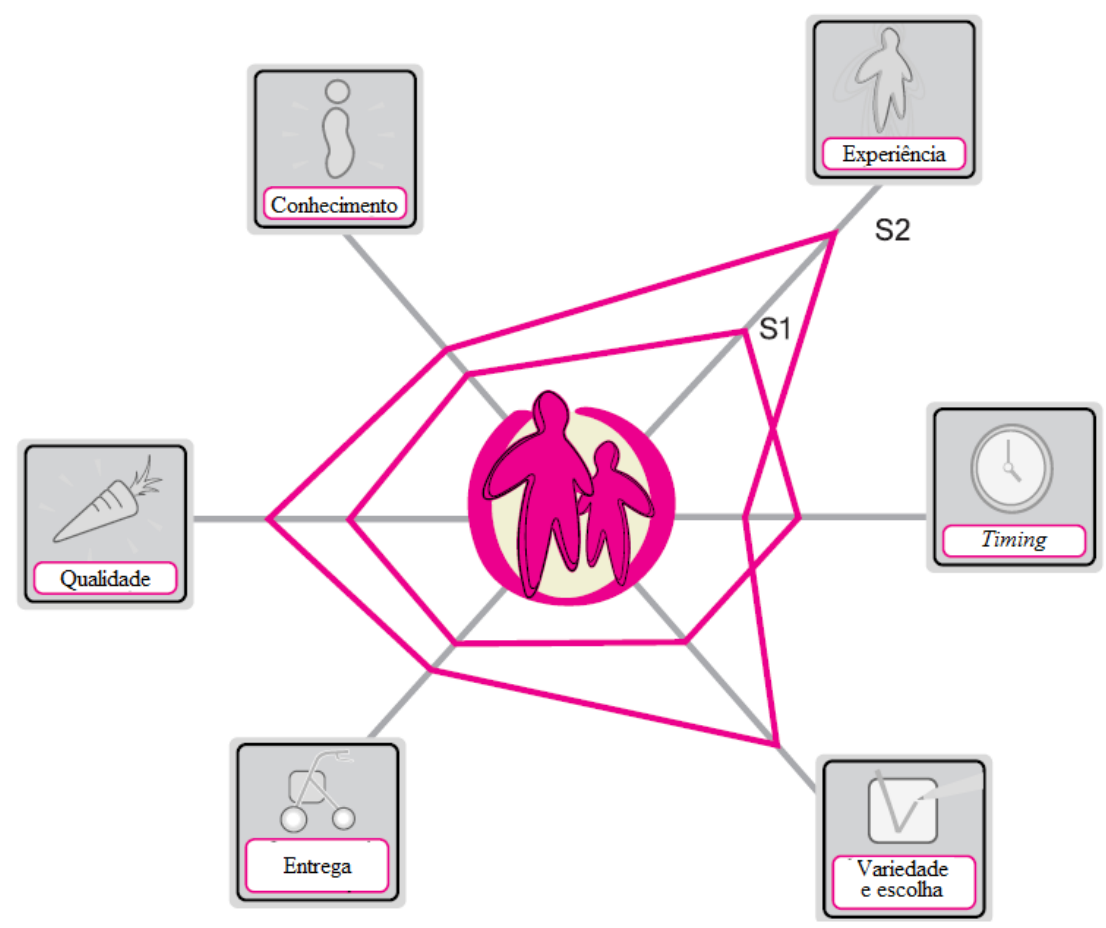

Figura 4: Exemplo de avaliação social entre duas soluções (S1 e S2) (Traduzido e adaptado de Partidário, 2004).

Como base para iniciar as pesquisas em PSS, realizou-se uma busca nas bases de dados (Scopus e Web of Science) de trabalhos intitulados como "review" e "state-of-theart" (Quadro 1), pois a partir deles foi possível observar a tendências e oportunidades de pesquisas em PSS, a relevância do tema e os principais autores. Obteve-se os seguintes quantitativos de artigos disponíveis nas bases: 
Quadro 1: Quantidade de trabalhos pesquisados.

\begin{tabular}{|c|c|c|c|}
\hline Tema & Filtros & SCOPUS & $\begin{array}{c}\text { WEB of } \\
\text { Science }\end{array}$ \\
\hline \multirow{5}{*}{$\begin{array}{c}\text { Palavra-chave: PSS ("product-service } \\
\text { system") }\end{array}$} & $\begin{array}{c}\text { SCOPUS Filtros: } \\
\text { engineering; business; } \\
\text { economics; decision }\end{array}$ & 1364 & - \\
\cline { 2 - 4 } & $\begin{array}{c}\text { WEB: Engineering; business } \\
\text { economics; } \text { operations } \\
\text { research management } \\
\text { science }\end{array}$ & - & 417 \\
\cline { 2 - 4 } & Article + journal & $\mathbf{3 9 2}$ & $\mathbf{1 7 7}$ \\
\hline
\end{tabular}

Nesse primeiro levantamento de artigos, foi realizado uma seleção dos artigos mais relevantes e citados para compor a revisão bibliográfica deste trabalho. Alguns dos principais autores foram Goedkoop et al (1999), Mont (2002), Manzini e Vezzoli (2003), Tukker (2004), Morelli (2006), Krucken e Meroni (2006), Evans et al (2007), Baines et al (2007) e Wang et al (2011),

Com base no mesmo levantamento, um novo filtro de palavras chave foi utilizado para refinar as pesquisas em avaliação do desempenho de um PSS ("performance") e sustentabilidade ("sustainability"). A partir desses filtros constatou-se uma gama de autores que avaliaram o desempenho de um sistema produto-serviço por meio de indicadores relacionados às dimensões da sustentabilidade.

A partir dessa revisão, realizou-se uma seleção dos indicadores da sustentabilidade relacionadas com o desempenho do PSS (Tabela 1).

Tabela 1: Indicadores da sustentabilidade relacionados ao desempenho do sistema.

\begin{tabular}{|c|l|c|}
\hline Dimensão & \multicolumn{1}{|c|}{ Indicadores } & Autor(es) \\
\hline Ambiental & $\begin{array}{l}\text { Desperdício; Recursos hídricos; Recursos } \\
\text { materiais; Transporte; Uso de energia }\end{array}$ & $\begin{array}{c}\text { SUNDIN et al } \\
\text { (2015) }\end{array}$ \\
\hline $\begin{array}{c}\text { Ambiental, } \\
\text { Econômico }\end{array}$ & $\begin{array}{l}\text { Emissões de poluentes; Recursos de trabalho; } \\
\text { Depreciação; Fontes renováveis de energia; uso } \\
\text { de materiais }\end{array}$ & $\begin{array}{c}\text { VOGTLANDER et } \\
\text { al (2002) }\end{array}$ \\
\hline $\begin{array}{c}\text { Ambiental, } \\
\text { Econômico, } \\
\text { Social }\end{array}$ & $\begin{array}{l}\text { Consumo de energia; Emissões de poluentes; } \\
\text { Orçamento; Lucro; Saúde humana }\end{array}$ & LEE et al (2012) \\
\hline
\end{tabular}

Continua 
Continuação

\begin{tabular}{|c|c|c|}
\hline $\begin{array}{c}\text { Ambiental, } \\
\text { Econômico, } \\
\text { Social }\end{array}$ & $\begin{array}{l}\text { Custo de inventário; Custo da mão de obra; } \\
\text { Custo de material; Materiais substitutos; } \\
\text { Entrega de produtos; Emissão de ar; Consumo } \\
\text { de energia; Consumo de combustível; Consumo } \\
\text { de materiais; Taxa de acidentes; Relações de } \\
\text { trabalho; Saúde e segurança ocupacional; } \\
\text { Treinamento e educação }\end{array}$ & $\begin{array}{l}\text { AMRINA \& VILSI } \\
\qquad(2015)\end{array}$ \\
\hline $\begin{array}{l}\text { Ambiental, } \\
\text { Econômico }\end{array}$ & $\begin{array}{l}\text { Consumo de energia; Lead time; Volume de } \\
\text { produção; (os indicadores foram listados de } \\
\text { forma agrupada e reduzida para melhor } \\
\text { compreensão) }\end{array}$ & $\begin{array}{c}\text { FANTINI et al } \\
\text { (2015) }\end{array}$ \\
\hline $\begin{array}{c}\text { Ambiental, } \\
\text { Econômico, } \\
\text { Social }\end{array}$ & $\begin{array}{l}\text { Consumo de energia; Quantidade de resíduos; } \\
\text { Quantidade de materiais não renováveis; } \\
\text { Substâncias restritas; Consumo de água; } \\
\text { Volume de ar; Custo de investimento; } \\
\text { Produtividade; Horas trabalhadas }\end{array}$ & LINKE et al (2013) \\
\hline $\begin{array}{r}\text { Econômico, } \\
\text { Ambiental }\end{array}$ & $\begin{array}{l}\text { Utilização do espaço de trabalho; Estoque de } \\
\text { peças novas; Estoque de peças retrabalhadas; } \\
\text { Tempo de operação; Tempo de espera do } \\
\text { consumidor; Quantidade de clientes atendidos; } \\
\text { Quantidade clientes recuperados pelo uso de } \\
\text { peças retrabalhadas; Emissão de CO2 }\end{array}$ & $\begin{array}{l}\text { RONDINI et al } \\
\text { (2017) }\end{array}$ \\
\hline $\begin{array}{c}\text { Econômico, } \\
\text { Ambiental, } \\
\text { Social }\end{array}$ & $\begin{array}{l}\text { Aquecimento global; Redução abiótica; } \\
\text { Acidificação; Eutrofização; Toxicidade da } \\
\text { água; Toxicidade humana; Toxicidade marinha; } \\
\text { Redução da camada de ozônio; Poluição } \\
\text { atmosférica; Toxicidade terrestre; Custo capital; } \\
\text { Custo anual; Custo per capta; Proteção e } \\
\text { diversidade de fornecimento; Aceitabilidade } \\
\text { pública; Saúde e segurança; Questões } \\
\text { intergeracionais. }\end{array}$ & $\begin{array}{c}\text { SANTOYO- } \\
\text { CASTELAZO e } \\
\text { AZAPAGIC (2014) }\end{array}$ \\
\hline
\end{tabular}


Continuação

\begin{tabular}{|c|l|l|l|}
\hline & $\begin{array}{l}\text { Aparência do produto, Usabilidade do produto, } \\
\text { Responsividade e empatia, Garantia e } \\
\text { Econômico, } \\
\text { confiabilidade, Segurança e saúde, Estilo de } \\
\text { vida verde, Aprendizado, Preço percebido, } \\
\text { Social }\end{array}$ & $\begin{array}{l}\text { Equidade, Ciclo de vida do produto, Consumo } \\
\text { de energia, Consumo de água, Geração e } \\
\text { emissão de poluentes, Conflitos culturais, Custo }\end{array}$ & CHOU et al (2015) \\
adaptado \\
de manufatura, Custo dos serviços, Consumo de \\
materiais, Horas trabalhadas.
\end{tabular}

Fonte: Elaborado pelo autor (2019).

Devido a necessidade de avaliação do desempenho de fabricação sustentável, o desenvolvimento de métricas adequadas se faz fundamental para permitir que designers, engenheiros e gerentes orientem seus processos de decisão, desde o planejamento de fábrica até operações, gerenciamento e controle. Um Indicador de Desempenho Chave (KPI) é, durante a Operação, um item de informação coletada em intervalos regulares para rastrear o desempenho de uma organização ou sistema em qualquer nível (como máquina de produção ou planta ou unidade) que produz saída (produtos ou serviços) usando recursos de tipos diferentes. Durante o processo de design, o KPI pode ser usado para comparar o desempenho de tecnologias alternativas ou sistemas de fabricação e o trade-off com quantidades e custos do uso relevante de recursos. Reconheceu-se que as futuras eco fábricas sustentáveis devem ser vistas como uma rede complexa de interdependências entre os vários produtos/materiais e fluxos de recursos com os sistemas de gerenciamento e controle de fábrica. (FANTINI et al, 2015)

Vogtlander et al (2002) trabalharam com indicadores de eco eficiência em um modelo que descreve a sustentabilidade da combinação de produto-serviço de pós-venda e manutenção de fogões com aquecimento por placa de indução. Os autores combinaram os aspectos econômicos e ambientais por meio de "eco-custos" relacionados a emissões de poluentes, fontes de energias renováveis, uso de materiais, depreciação de equipamentos e dos recursos utilizados no trabalho. O modelo proposto está direcionado 
para atender estratégias que melhorem a relação de valor e custo de um projeto sustentável. Os autores concluíram que o conjunto de indicadores utilizados no modelo ajudaram gerentes e consumidores com relação a decisões de interesse ambiental em comparação se tivessem como base apenas um indicador.

Sundin et al (2015) estudaram três empresas de pequeno e médio porte em fase de transição para o PSS de modo a relacionar as características delas com a sustentabilidade. Os autores focaram em indicadores de aspecto ambiental e identificaram que o tamanho e a maturidade da empresa influenciam diretamente em quanto e quão desenvolvido estão os indicadores. As referências utilizadas foram de órgãos internacionais que provêm iniciativas e requisitos relacionados ao desenvolvimento da sustentabilidade como a OECD (Organisation for Economic Co-operation and Development) e a ISO (International Organization for Standardization).

No contexto da avaliação de sustentabilidade de um PSS, a maioria dos estudos enfatizam o aspecto "ambiental", provavelmente, porque ele é mensurado com relativa facilidade (MOURTZIS et al, 2015).

Lee et al (2012) trataram a muldimensionalidade da sustentabilidade por meio da abordagem TBL (Triple Bottom Line) a qual integra os aspectos ambientais, econômicos e sociais, capturando um amplo espectro de medição do sucesso organizacional. Os autores utilizaram indicadores de sustentabilidade baseados no Global Reporting Initiative (GRI), como a redução no consumo de energia, a redução de emissão de poluentes no ar, redução do orçamento, lucratividade das partes interessadas e o estado de saúde das pessoas. Por meio de simulação dinâmica, os autores concluíram que a abordagem TBL pode ser usada para identificar o comportamento a longo prazo da sustentabilidade do PSS, levando em consideração a interdependência entre os três pilares da sustentabilidade. Como uma ferramenta de medição dinâmica e multidimensional que considera os recursos da sustentabilidade do PSS, essa abordagem pode ser efetivamente empregada para avaliar várias alternativas PSS ou para analisar conceitos PSS.

Amrina \& Vilsi (2015) utilizaram e selecionaram KPIs para avaliação da sustentabilidade baseados nas organizações GRI, ISO e a OECD utilizando a abordagem TBL e a opinião de especialistas. Os autores focaram o trabalho na avaliação da performance sustentável no ambiente da manufatura de uma indústria de cimento por meio de 13 indicadores validados pelos gerentes de produção da fábrica. A medição, feita por uma escala de 10 pontos variando desde muito pobre (baixa performance) até 
excelente (alta performance), proporcionou direcionamentos para ajudar as empresas a alcançarem alta performance e serem competitivas.

Para Fantini et al (2015), os indicadores de sustentabilidade compartilham uma visão externa comum da fabricação, com base na medição dos diferentes tipos de fluxos relevantes ambientais e econômicos, tais como material, energia e outros recursos; emissões, desperdícios e outros poluentes, custos, etc. Os indicadores de sustentabilidade, de fato, são calculados através da avaliação, comparação, correlação de quantidades durante um período de tempo especificado. $\mathrm{O}$ modelo proposto pelos autores permite capturar toda performance nas perspectivas econômicas e ambientais conectadas com o ambiente de manufatura.

Ainda com foco na manufatura, Linke et al (2013) selecionaram indicadores de sustentabilidade relacionados com a performance dos processos de esmerilhamento. Os autores aconselharam o uso de poucos indicadores para se obter uma análise de resultados mais gerenciável, por isso elencaram 9 indicadores relacionados aos três aspectos da sustentabilidade.

A aplicação prática dos indicadores de sustentabilidade aos processos de fabricação raramente é documentada. Os indicadores de sustentabilidade são baseados em dados medidos e/ou estimados que devem ser normalizados, escalados e agregados consistentemente, ou seja, eles não apresentam seu valor como valor absoluto, mas mostram termos relativos como uma relação de desempenho por unidade de produção específica (LINKE et al, 2013).

Santoyo-Castelazo e Azapagic (2014) propuseram um modelo integrado da sustentabilidade na avaliação de sistemas de energia, considerando as mudanças climáticas propostas por órgãos como Greenpeace e OECD, de modo a contribuir para tomada de decisões com relação ao plano de fornecimento de energia para o futuro. Os autores constataram que não existem soluções/cenários ideais quando se trata de multicritérios da sustentabilidade, gerando assim trade-offs que levam a decisões "mais sustentáveis" para o setor de energia. O cenário mais atrativo mostrou $86 \%$ de contribuição para fontes renováveis, entretanto, a viabilidade técnica deste cenário foi incerta devido a uma penetração muito alta de energias renováveis que, além das questões de intermitência e capacidade de carga básica, supera o potencial atualmente estimado para algumas das energias renováveis.

Para vincular produtos e serviços à sustentabilidade, Chou et al (2015) utilizaram a eco-eficiência como conceito e referência na avaliação de dois cenários de uma 
fabricante de utensílios de cozinha. Ambos cenários ofertavam serviços de reparo, manutenção e reciclagem, mas com a diferença de que em um cenário adicionaram o serviço de entregas e, no outro, o serviço de treinamento para melhor uso e compartilhamento dos utensílios. Os autores categorizaram em dois atributos fundamentais sob a ótica do PSS (percepção do cliente e percepção do empregado) e dois sob a ótica da sustentabilidade (impacto sobre o cliente e a empresa), sendo todos divididos em subcategorias totalizando 74 indicadores medidos.

Rondini et al (2017) construíram modelos de simulação os quais representassem o processo de entrega de um serviço de manutenção de caminhões e, para isso, utilizaram indicadores de performance orientados indiretamente aos aspectos ambientais e econômicos, ou seja, a abordagem dada no estudo foi mais direcionada à simulação e menos aos conceitos dos pilares da sustentabilidade.

Com base nos resultados obtidos pelos autores, observou-se que seis deles estão estruturados na forma de modelo.

Os modelos de Vogtlander et al (2002), Linke et al (2013) e Rondini et al (2017) seguem uma representação de diagrama de fluxo com entradas e saídas em um sequenciamento de etapas. As figuras 5, 6 e 7 ilustram esquematicamente cada um deles, respectivamente.

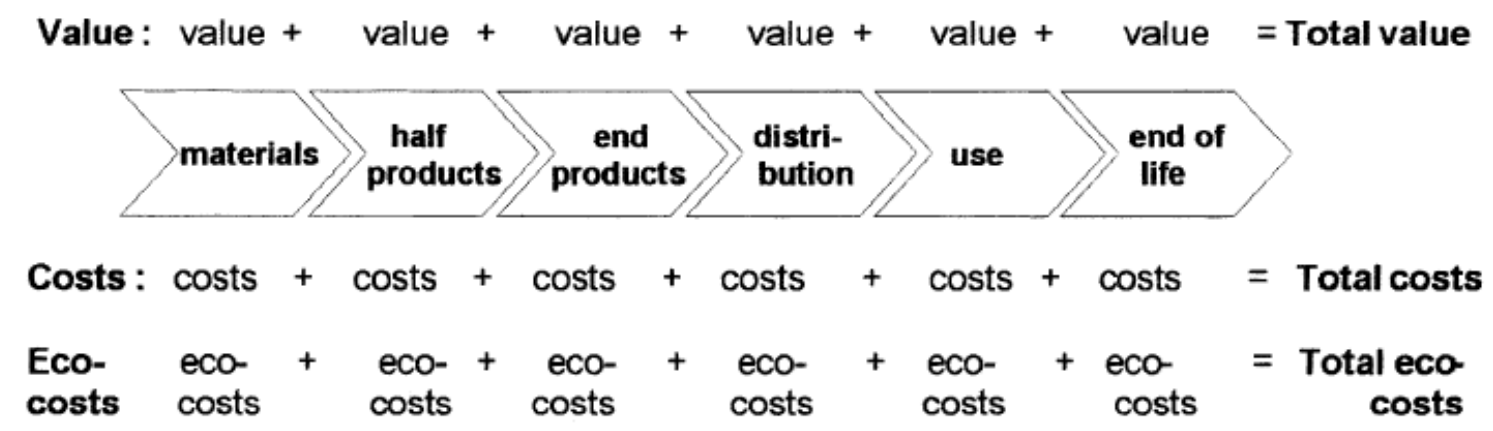

Figura 5: Modelo de pesquisa de Vogtlander et al (2002). 


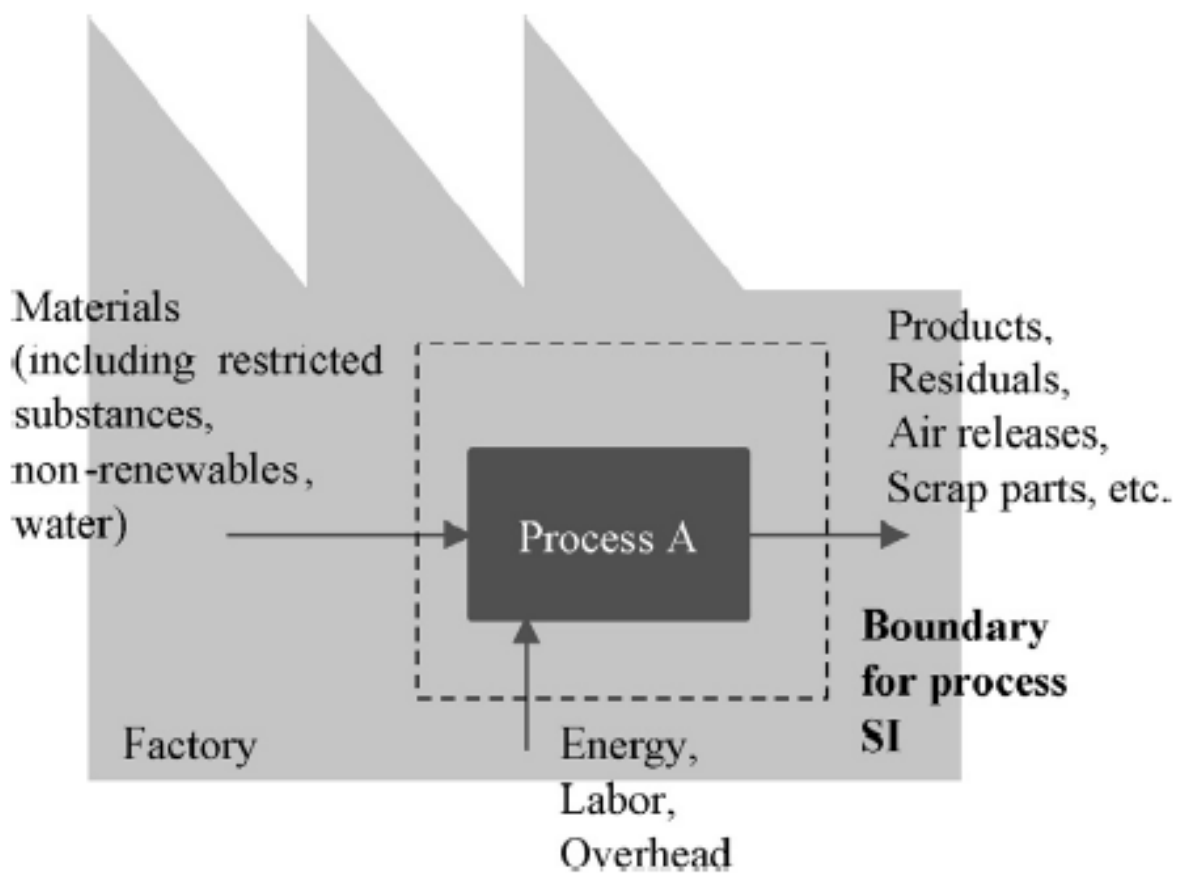

Figura 6: Modelo de pesquisa de Linke et al (2013).

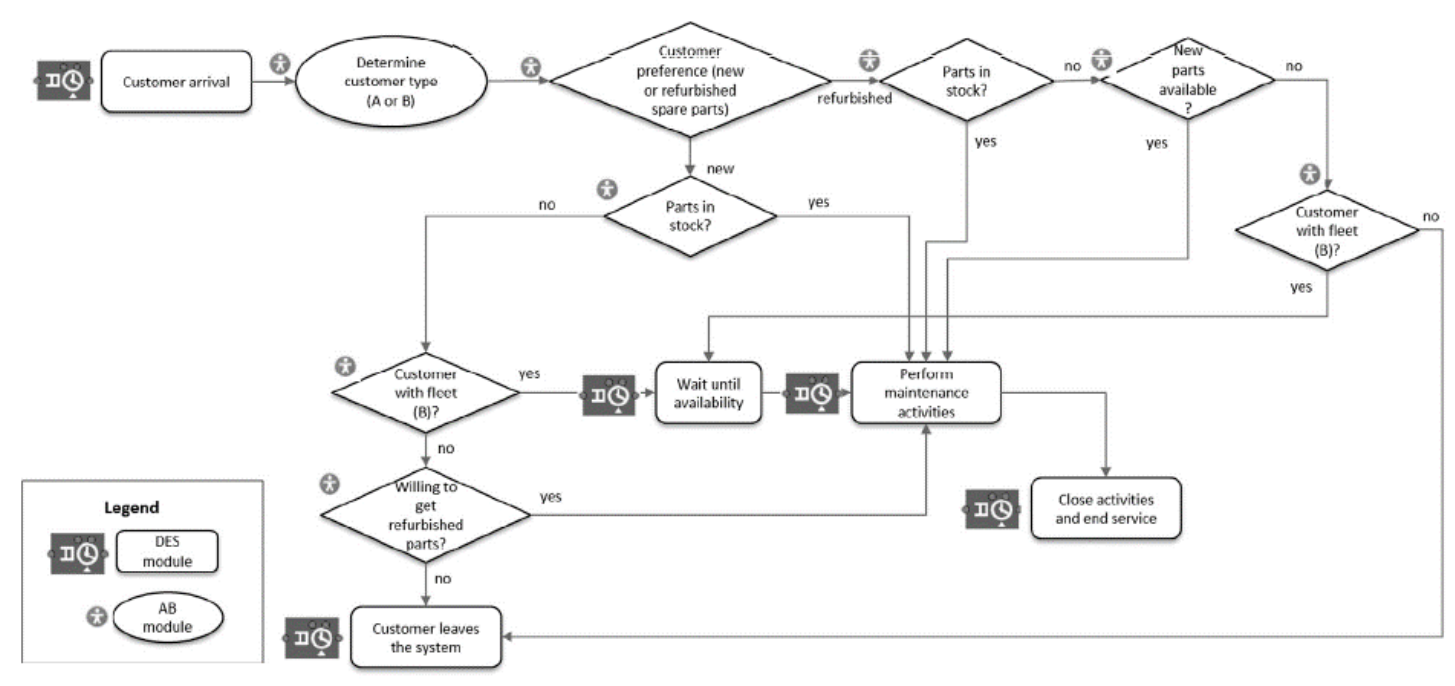

Figura 7: Modelo de pesquisa de Rondini et al (2017).

O modelo de Amrina e Vilsi (2015) é mais conceitual e representado por um quadro com a listagem dos indicadores utilizados em seu trabalho (Figura 8). 


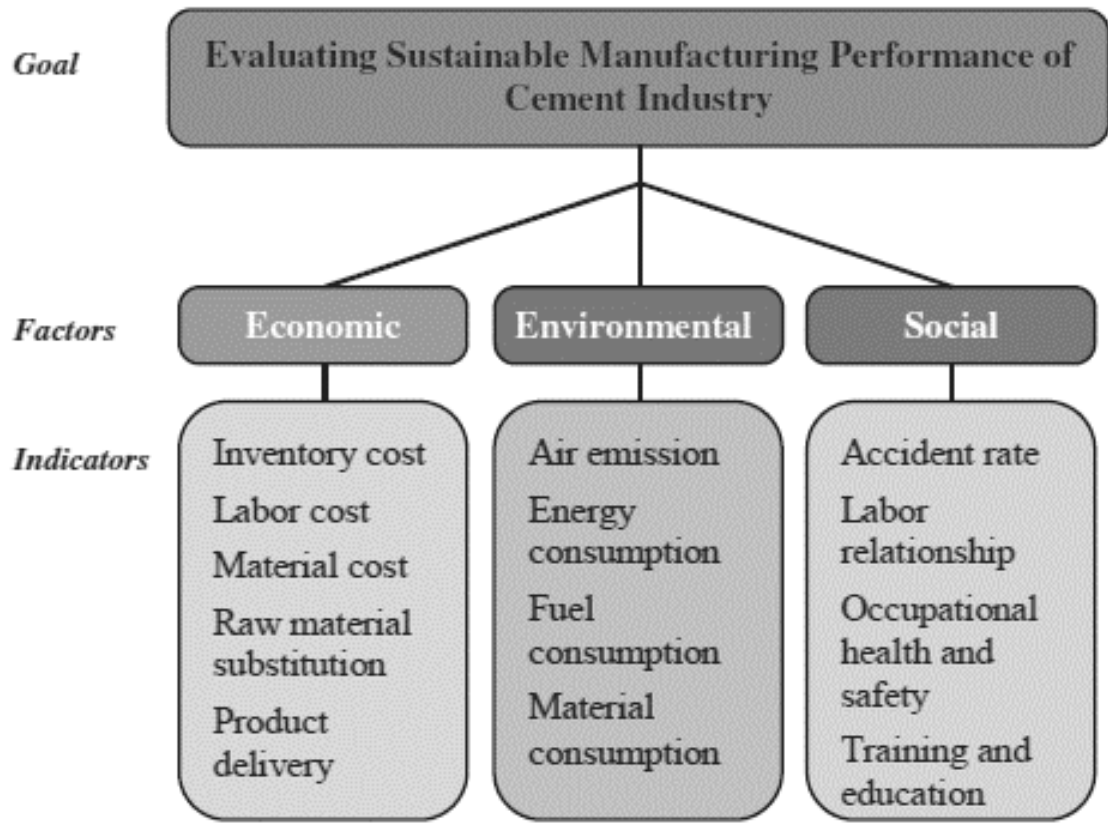

Figura 8: Modelo de pesquisa de Amrina e Vilsi (2015).

Por fim os modelos de Fantini et al (2015) e Lee et al (2012) têm como representação as relações entre as dimensões da sustentabilidade por meio de diagramas de laço causal, e estão ilustrados nas figuras 9 e 10 respectivamente.

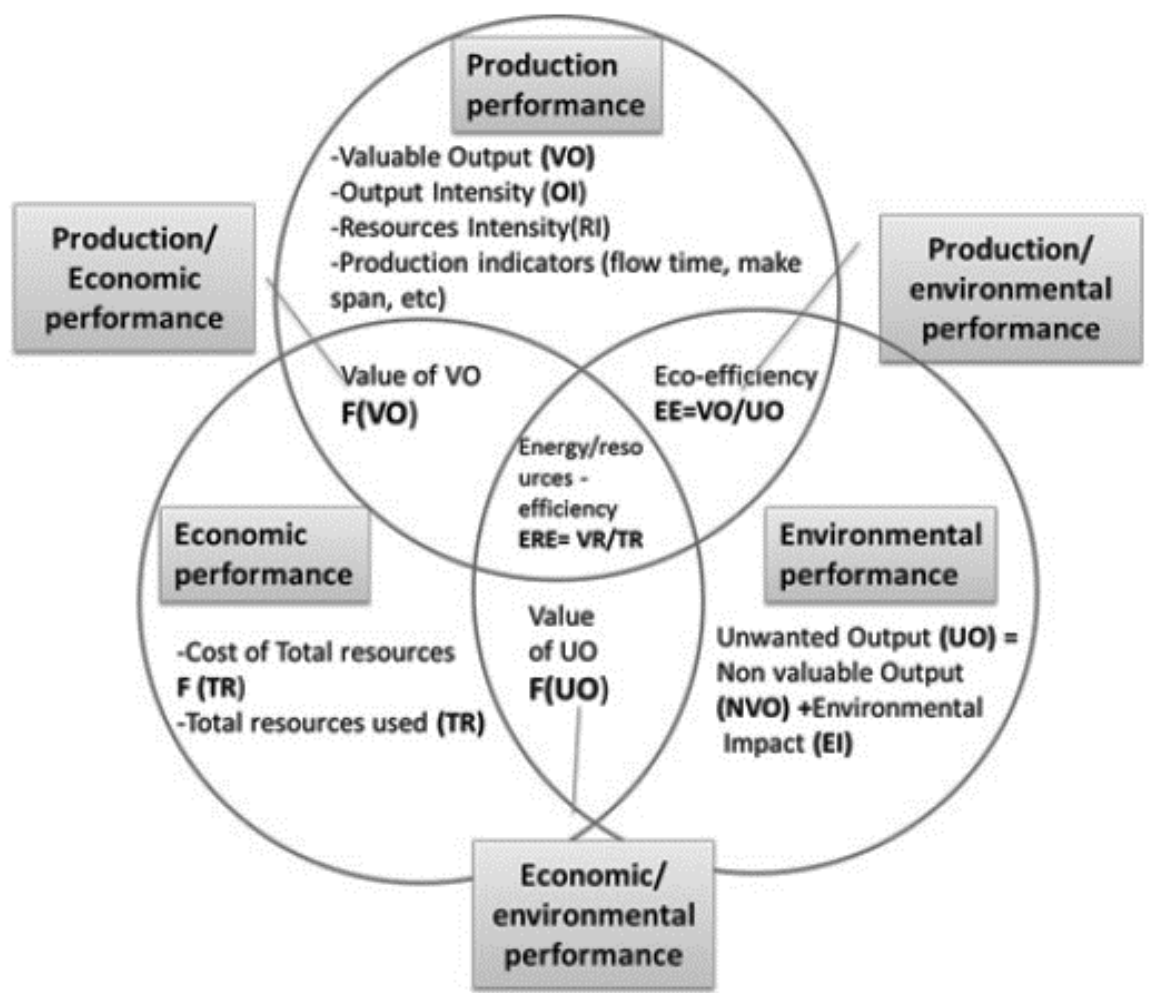

Figura 9: Modelo de pesquisa de Fantini et al (2015). 


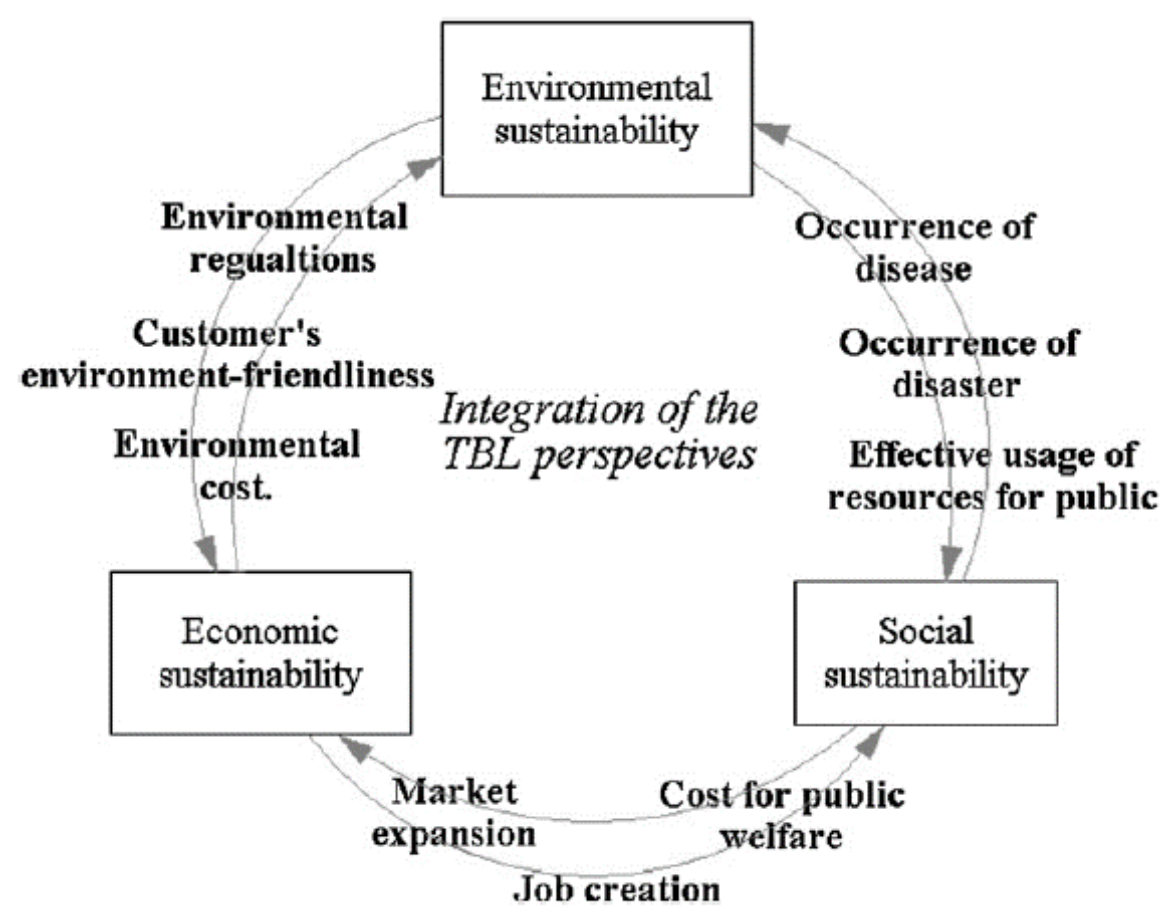

Figura 10: Modelo de pesquisa de Lee et al (2012).

\subsubsection{SIMULAÇÃO COMO FERRAMENTA DE ANÁLISE}

Avaliar a contribuição de uma determinada atividade para a sustentabilidade é difícil por uma série de razões. Primeiro, o conceito de sustentabilidade é abrangente, tanto temporal como geograficamente. Em segundo lugar, o nível de complexidade em questões de estudo pode ser muito alto não só por causa do amplo escopo a tratar, mas também por múltiplas interações a serem consideradas entre os elementos econômicos, ambientais e sociais. Em terceiro lugar, as interações entre os componentes críticos em questão geralmente não são deterministas. Estes problemas podem ser manuseados melhor por modelagem de simulação do que qualquer outro método disponível. A simulação pode ser usada para comparar vários planos e cenários antes da implementação, prever comportamentos de um sistema, desenvolver uma melhor compreensão e conhecimento de um sistema, auxiliar nos processos de tomada de decisão, desenvolver novas ferramentas de investigação e treinamento (MOON, 2016).

Rondini et al (2017) realizaram um trabalho com modelagem e simulação como ferramenta para análise de um PSS sustentável. Baseados no processo e com foco no serviço, compararam três tipos de simulação: DES (Simulação de Eventos Discretos), ABM (Modelagem de Agentes Base) e SD (Sistemas Dinâmicos), com abordagens hibridas, ou seja, o efeito da combinação dos tipos de simulação em relação a uma 
abordagem singular. Os testes mostraram que as abordagens hibridas e singulares são capazes de medir os KPI's relacionados aos processos do PSS.

A Modelagem e Simulação de Eventos Discretos (DEMS) deriva seu nome do mecanismo básico que as variáveis de estado de um sistema mudam somente em pontos discretos e separados no tempo. Os eventos ocorrem nesses momentos e são os únicos casos em que o estado do sistema muda. A DEMS tipicamente modela um sistema complexo como uma sequência ordenada de eventos, mesmo que sequências complicadas e estruturas hierárquicas possam ser empregadas. As incertezas associadas aos eventos podem ser modeladas explicitamente e suas consequências coletivas no sistema são analisadas estatisticamente (MOON, 2016).

A DEMS pode suportar o PSS na combinação e variação desses fatores (por exemplo, incertezas, recursos e tabelas de tempo) para comparar vários cenários possíveis. No processo de desenvolvimento precoce, a fase de planejamento, a simulação pode avaliar muitos cenários em diferentes condições de fronteira. Por um lado, as configurações ideais podem ser definidas e, por outro lado, oportunidades e riscos podem ser identificados. No estágio inicial, as mudanças na operação futura podem ser preparadas e os gargalos identificados. Isso reduz o risco de uma configuração errada e as influências atualmente não previsíveis podem ser antecipadas. Os sistemas sem uma característica do fluxograma são difíceis de representar na lógica DEMS (WEIDMANN et al, 2015).

De forma complementar, os autores explicaram que um PSS orientado a resultado, os provedores são capazes, por meio da DEMS, de estimar o tempo de ciclo de um determinado cenário e informar o cliente sobre o tempo e custo da operação diminuindo a preocupação dele (WEIDMANN et al, 2015).

\subsection{SISTEMAS DE ALIMENTAÇÃO}

\subsubsection{O SETOR DE ALIMENTOS}

O setor de alimentos tem uma importância estratégica na economia global e engloba muitos atores heterogêneos que precisam se inter-relacionar constantemente com a variedade de demandas de clientes, usuários finais e legisladores, mas também com

ciclos de vida mais curtos, padrões de qualidade mais elevados, segurança alimentar e competitividade (ARCESE et al, 2015). 
O setor de alimentos representa cerca de $10 \%$ do Produto Interno Bruto (PIB) e o faturamento das empresas somou R \$ 431,9 bilhões no País, em 2012, sendo R \$ 353,9 bilhões em alimentos e R $\$ 78$ bilhões em bebidas. Esse desempenho coloca o setor como o $1^{\circ}$ maior em valor bruto de produção da indústria de transformação, segundo a Associação Brasileira das Indústrias da Alimentação (INVESTESP, 2017).

Acompanhando essa tendência, o setor de food service tem crescido, na última década, em velocidade maior do que as taxas de crescimento do varejo alimentício. No período 2006-2016, teve um crescimento médio de $14 \%$ ao ano, contra $11 \%$ do varejo. No ano passado, teve faturamento de 154 bilhões, com crescimento de 7,1\% em comparação com 2015 (ABIA, 2017).

A indústria de alimentos tem estado sujeita a uma série de mudanças na sociedade e precisou responder a mudanças técnicas e econômicas de longo alcance na produção e processamento de alimentos (BAREGHEH et al, 2012)

\subsubsection{SERVIÇOS DE ALIMENTAÇÃO/REFEIÇÕES COLETIVAS}

As empresas estão cada vez mais focadas em competitividade e acabam terceirizando seus negócios não essenciais como alternativa de redução de custos como, por exemplo, a contratação de serviços de alimentação.

A dimensão e a importância desse setor na economia nacional podem ser medidas a partir dos números gerados pelo segmento no ano 2016 - o mercado de refeições coletivas como um todo fornece 11 milhões de refeições/dia, movimenta uma cifra de 16,9 bilhões de reais por ano, oferece 180 mil empregos diretos, consome diariamente um volume de 5,8 mil toneladas de alimentos e representa para os governos uma receita de 2 bilhões de reais anuais entre impostos e contribuições (ABERC, 2017).

Das 11 milhões de refeições em 2016 cerca de 90\% são fornecidas pelas 90 empresas prestadoras de serviço filiadas a ABERC, que juntas responsabilizam-se por 95\% (noventa e cinco por cento) do volume desse mercado (ABERC, 2017).

De maneira sucinta, os serviços de alimentação são compostos por 3 etapas principais: aquisição, produção e serviço. A aquisição consiste na seleção dos fornecedores de acordo com as especificações da matéria-prima, realização da compra e recebimento, e por fim, armazenamento em local adequado. A produção consiste no preparo das refeições em quantidades padronizadas com a qualidade requerida e no tempo estipulado. E por fim, o serviço é o atendimento ao cliente de acordo com suas necessidades (AHMED et al, 2015). Quando comparado aos arranjos de suporte 
tradicionais, o conceito PSS altera as funções e as responsabilidades de um contratante ao mudar o serviço de suporte para o foco do cliente. Sob os arranjos orientados para o serviço, o provedor de serviços é responsável pelo espectro completo de suporte, incluindo a propriedade, sustentação e operação de ativos (MO, 2012)

Além disso, os acordos de contratação incluirão incentivos e penalidades em relação aos níveis de serviço de suporte ou entrega. O provedor de serviços precisará pensar de forma diferente e projetar as soluções de saída que fornecem os resultados desejados, além de gerar lucros. Este é um tipo de negócio diferente com métricas e riscos contratuais desconhecidos (MO, 2012). No caso da prestação de serviços de alimentação, a empresa contratada fatura de acordo com a quantidade de refeições servidas, e não pela quantidade de refeições produzidas.

Atividades de gestão ou terceirização não costumam exigir mudanças radicais relacionadas à organização e tecnologia, entretanto, as empresas provedoras do PSS devem ser competitivas em relação à eficiência do serviço prestado, fazendo o uso eficiente de materiais e recursos (TUKKER, 2004).

Tukker (2015) relata a necessidade de investimento na produção de PSS. A maioria das empresas começam puramente com a venda de um produto ou como provedor de serviços e precisa desenvolver competências e capacidades totalmente novas. Além disso, o negócio do PSS pode ter novos canais de fornecimento e práticas de produção que possam competir com o negócio de vendas de produtos existentes, levando a depreciação do capital.

\subsubsection{PROCESSAMENTO MINIMO DE VEGETAIS}

Os produtos minimamente processados ou frescos são frutas e legumes frescos prontos para uso ou prontos para uso que foram lavados, picados e embalados em filmes ou bandejas poliméricas seladas. A demanda por vegetais aumentou continuamente durante os últimos anos, sendo o fator de conveniência o principal motivo para o crescimento, embora agora a tendência alimentar saudável esteja ajudando a tornar este setor ainda mais forte (GHIDELLI; PÉREZ-GAGO, 2016).

As operações envolvidas na produção de frutas e vegetais minimamente processadas (VMP) visam garantir segurança, qualidade e redução de perdas dos produtos. As etapas principais da cadeia de processamento que afetam a qualidade dos produtos, como lavagem, corte, sanitização e embalagem são comuns nas linhas de processo. (CENCI, 2011) 
Dentre as soluções encontradas para o desenvolvimento de novos produtos alimentícios, está o processamento mínimo de vegetais (PMV). Se por um lado a tecnologia de PMV agrega valor à matéria-prima para o agricultor e o processador, fornece para o consumidor conveniência e melhor manutenção da qualidade sensorial e nutricional presente nos produtos vegetais (CENCI, 2011).

Deste modo, um dos grandes desafios das empresas da cadeia de PMV é garantir a segurança de seus produtos de acordo com os requisitos necessários, desde a produção da matéria-prima (no campo), passando pelo processamento, pela armazenagem e pelo transporte, até a sua distribuição e comercialização (CENCI, 2011).

A partir da revisão bibliográfica e dos modelos dos principais autores referenciados neste trabalho, pôde-se construir um modelo capaz de representar o sistema produto-serviço de uma empresa de refeições coletivas.

O modelo apresenta os indicadores da sustentabilidade relacionados com os cenários e o resultado operacional da empresa para dar base para discussão do desempenho do sistema.

Como procedimento, o modelo foi validado para a construção dos cenários operacionais baseados em algumas estratégias que a empresa propõe, como:

- Produção de VMP somente para operação Delivery (operação atual)

- Produção de VMP para a operação In Company (existe demanda)

- Produção de VMP para o mercado varejista (estratégia futura)

Em seguida o objeto de estudo será detalhado a ponto de relatarmos como foi realizada a coleta e a validação dos dados do mesmo os quais serão utilizados como parâmetros para a construção do modelo de simulação.

Em resumo, este capitulo irá tratar dos seguintes pontos:

- Modelo de pesquisa

- Procedimentos utilizados na condução do trabalho de pesquisa de campo

- Detalhamento do objeto de estudo 
- Coleta dos dados do sistema

- Validação dos cenários propostos pela empresa

\subsection{MODELO DE PESQUISA}

O modelo de pesquisa foi elaborado para ser possível verificar a relação entre os diferentes cenários de um sistema de produção de refeições e os indicadores da sustentabilidade.

Assim, baseando-se em um modelo de cenários, o modelo de pesquisa foi construído de forma a contemplar os cenários operacionais e estratégicos bem como os aspectos da sustentabilidade. A figura 11 mostra uma visão geral do modelo de pesquisa.

O modelo contempla os principais indicadores relacionados à sustentabilidade e seu impacto no desempenho operacional da empresa. Entende-se por desempenho operacional a capacidade de produzir a quantidade necessária de VMP para atender à demanda do sistema.

O desempenho do sistema será dado pelos resultados dos indicadores da sustentabilidade e a relação com o desempenho operacional como informação adicional que ajudará na discussão dos resultados

O cenário 1 do modelo mostra que a matéria-prima passa pelo PMV e segue para a produção na cozinha da matriz da empresa e por fim a refeição pronta segue para o cliente para consumo final. No cenário 2 , houve a mudança da produção de refeições que fica alocada dentro da cozinha do cliente entregando assim o produto final juntamente com o serviço. Por fim, o cenário 3 não se trata exatamente de uma mudança operacional do sistema, mas sim uma mudança estratégica que a empresa se propôs a realizar no futuro. 


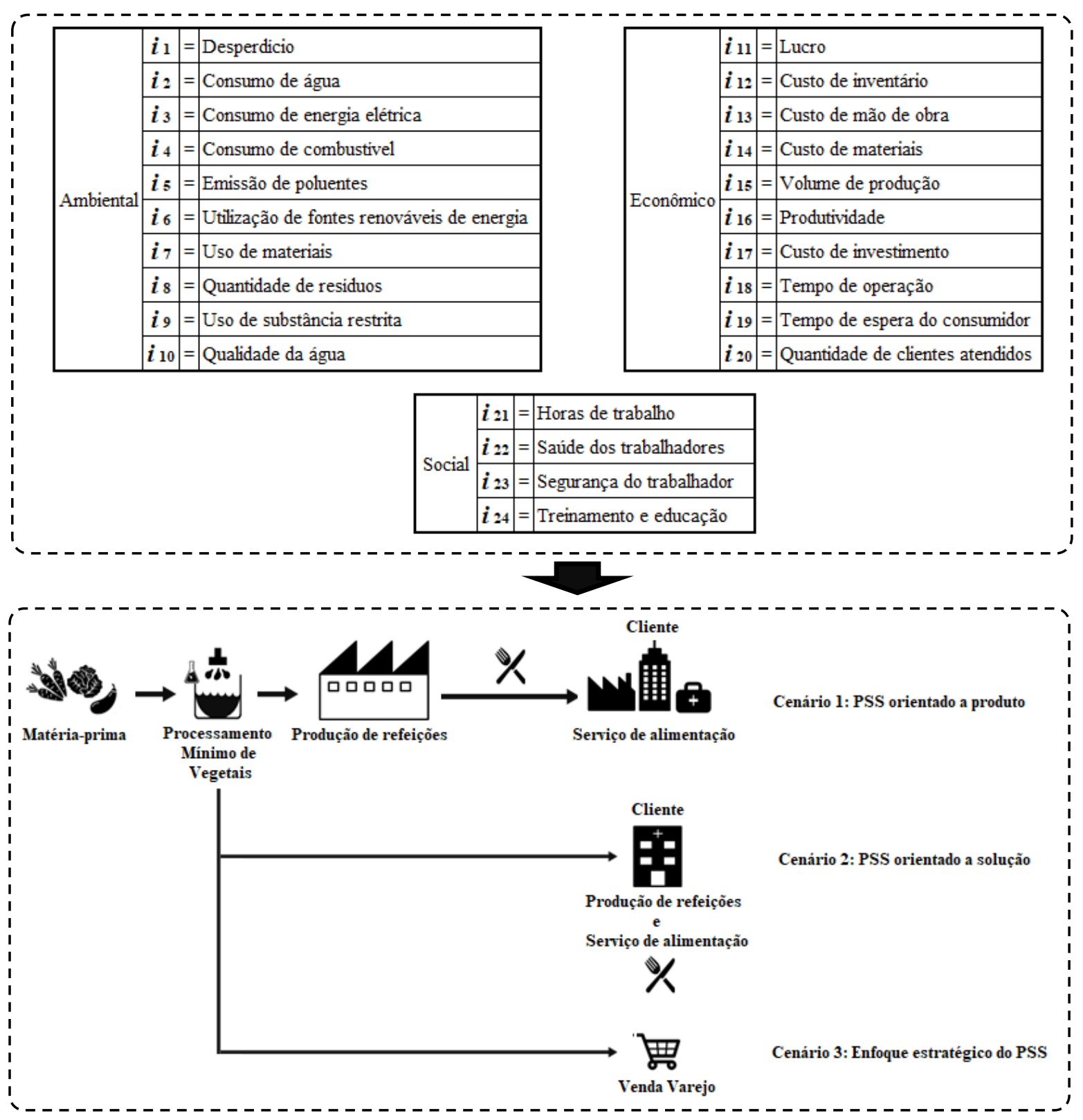

Figura 11: Modelo de pesquisa

De fato, o modelo de pesquisa baseado em cenários pode ser útil para os objetivos da presente pesquisa. Santoyo-Castelazo e Azapagic (2014) fizeram uso da análise de cenários para explorar futuros de energia alternativa e avaliar as implicações de sustentabilidade. Ao contrário da previsão, a análise de cenários não tem como objetivo prever o futuro, mas, em vez disso, considera possíveis futuros que podem ou não acontecer, fornecendo respostas para os tipos de perguntas de "what-if". O desenvolvimento de cenários depende de muitos fatores diferentes, incluindo fatores políticos e econômicos, como crescimento econômico, segurança do aprovisionamento e 
mitigação das mudanças climáticas, bem como o desenvolvimento tecnológico previsto no futuro.

O termo cenário é "considerado um sinônimo para uma visão geral de algo complexo e articulado - um conjunto de possíveis condições, ou transformações, que afetam o domínio em questão". Construir cenários é um processo que pode ajudar empresas e redes de negócios no desenvolvimento de novos produtos sustentáveis, PSS ou outros negócios. Como o desenvolvimento das ofertas de PSS em muitos casos é realizado com vários atores diferentes, é uma necessidade que os diferentes atores tenham uma visão compartilhada para que eles possam, finalmente, encontrar uma solução compartilhada. Além disso, a natureza da mudança de sistema necessária para alcançar a sustentabilidade inclui aspectos sociais, culturais, tecnológicos e organizacionais. Para poder fazer essa transição, a boa comunicação é essencial e pode ser facilitada pela construção de cenários. Existem vários tipos de cenários, como, por exemplo, previsão de gentileza, extrapolação de tendências, incursão e árvores de probabilidade (SUNDIN et al, 2015; MANZINI et al, 2009).

Os indicadores listados no modelo (10 indicadores ambientais, 10 econômicos e 4 sociais) foram selecionados a partir da tabela 1, contabilizando apenas os indicadores que pelo menos incidiram em mais de uma referência para que seja relevante serem tratados.

Os cenários propostos mostram que as estratégias de ampliação do fornecimento de VMP a serem adotadas pela empresa impactarão o sistema de produção atual influenciando na produção local de refeições. Os 24 indicadores serão medidos tanto na empresa como no cliente, se necessário, visto que a produção de refeições no cliente também poderá ser afetado pelas mudanças estratégicas.

Para validar o desempenho do sistema, será feito uma avaliação do desempenho operacional em termos de quantidade total produzida de VMP para cada cenário de modo a identificar a sua relação com os indicadores.

Após a coleta de dados, o modelo foi dividido em três cenários de modo a contemplar os cenários operacionais e estratégicos, centrados na manufatura, da empresa objeto de estudo. Para cada cenário construído, avaliou-se quais indicadores seriam pertinentes de análise de acordo com a realidade da empresa.

Para realizar a análise dos cenários, foi feita a modelagem e aplicado o método de simulação cujo detalhes são apresentados na seção 3.3.3. 
Na literatura, existe um grupo de autores (PARTIDÁRIO, 2004; MANZINI et al, 2004; MORELLI, 2006; PARTIDÁRIO et al, 2007; EVANS et al, 2007) que trabalharam com análise de desempenho do PSS contemplando as dimensões da sustentabilidade, porém com um enfoque nas parcerias feitas entre fornecedores, fabricantes e clientes. Entretanto, o método de conduzir a pesquisa (Tabela 2) que esses autores utilizaram se fez muito útil para a organização dos procedimentos do presente trabalho, principalmente pelo fato de utilizarem modelos baseados em cenários para as análises.

Tabela 2: Quadro resumo das etapas dos procedimentos da pesquisa.

\begin{tabular}{|c|c|c|c|}
\hline & Etapa & Descrição & $\begin{array}{l}\text { Capítulo } \\
\text { abordado }\end{array}$ \\
\hline 1 & Definição do objetivo & $\begin{array}{l}\text { "Avaliar o desempenho de um } \\
\text { PSS, com uma visão integrada dos } \\
\text { três aspectos da sustentabilidade: } \\
\text { econômico, ambiental e social, } \\
\text { pela construção de um modelo de } \\
\text { simulação de cenários estratégicos } \\
\text { centrados na manufatura de uma } \\
\text { empresa de refeições coletivas" }\end{array}$ & Capítulo 1.3 \\
\hline 2 & Definição do sistema & Empresa de refeições coletivas & Capítulo 3.3.1 \\
\hline 3 & $\begin{array}{l}\text { Definição do escopo da } \\
\text { análise }\end{array}$ & $\begin{array}{l}\text { Processamento mínimo de } \\
\text { vegetais }\end{array}$ & Capítulo 3.3 .2 \\
\hline 4 & $\begin{array}{l}\text { Definição de possíveis } \\
\text { unidades funcionais }\end{array}$ & Operação Delivery e In Company & $\begin{array}{l}\text { Capítulo } 3.3 .1 \mathrm{e} \\
3.3 .2\end{array}$ \\
\hline 5 & $\begin{array}{l}\text { Definição do tipo de } \\
\text { avaliação }\end{array}$ & $\begin{array}{l}\text { Quantitativa (Modelagem e } \\
\text { Simulação) e qualitativa (se } \\
\text { necessário) }\end{array}$ & Capítulo 3.3 .3 \\
\hline 6 & Seleção de indicadores & Ver Tabela 3.3.2 & $\begin{array}{l}\text { Capitulo } 3.1,3.2 \\
\text { e } 3.3 .2\end{array}$ \\
\hline 7 & Gerenciamento de dados & Entrevista para coleta de dados & Capitulo 3.3 .2 \\
\hline 8 & Avaliação & $\begin{array}{l}\text { Validação dos cenários de } \\
\text { simulação }\end{array}$ & Capitulo 3.3 .3 e 4 \\
\hline
\end{tabular}




\begin{tabular}{|l|l|l|l|}
\hline 9 & Comparando soluções & $\begin{array}{l}\text { Comparativo dos cenários } \\
\text { estratégicos }\end{array}$ & Capitulo 4 \\
\hline 10 & $\begin{array}{l}\text { Comunicação dos } \\
\text { resultados e conclusões }\end{array}$ & $\begin{array}{l}\text { Discussão dos resultados obtidos } \\
\text { na simulação }\end{array}$ & Capitulo 4 e 5 \\
\hline
\end{tabular}

\subsubsection{UNIDADE DE ANÁLISE}

A unidade funcional/objeto deste estudo (empresa X) trata-se de uma empresa de refeições coletivas com a matriz localizada na região metropolitana de São Paulo. A empresa $\mathrm{X}$ oferece soluções alimentícias como elaboração de cardápio, aquisição de insumos, preparação de refeições e a distribuição de refeições.

Seus principais clientes são hospitais, escolas, indústrias e empresas, totalizando mais de 40.000 refeições servidas por dia em aproximadamente 600 pontos de atendimento, espalhados em várias regiões do estado de São Paulo.

A cadeia de suprimentos é formada por aproximadamente 400 fornecedores, 30 pontos de recebimento, um centro de distribuição e mais de 100 rotas de entrega.

Os insumos (Figura 12) adquiridos são categorizados em alimentares e nãoalimentares, sendo os primeiros utilizados na preparação das refeições e categorizados basicamente como perecíveis e não-perecíveis, sendo a primeira composta por insumos de origem animal e vegetal, necessitando de controle de temperatura (abaixo da temperatura ambiente) e o segundo por grãos, farináceos, massas secas, desidratados, cereais, embutidos, entre outros que não necessitam de refrigeração para conservá-los. Os não-alimentares são compostos apenas por produtos descartáveis como embalagens. 


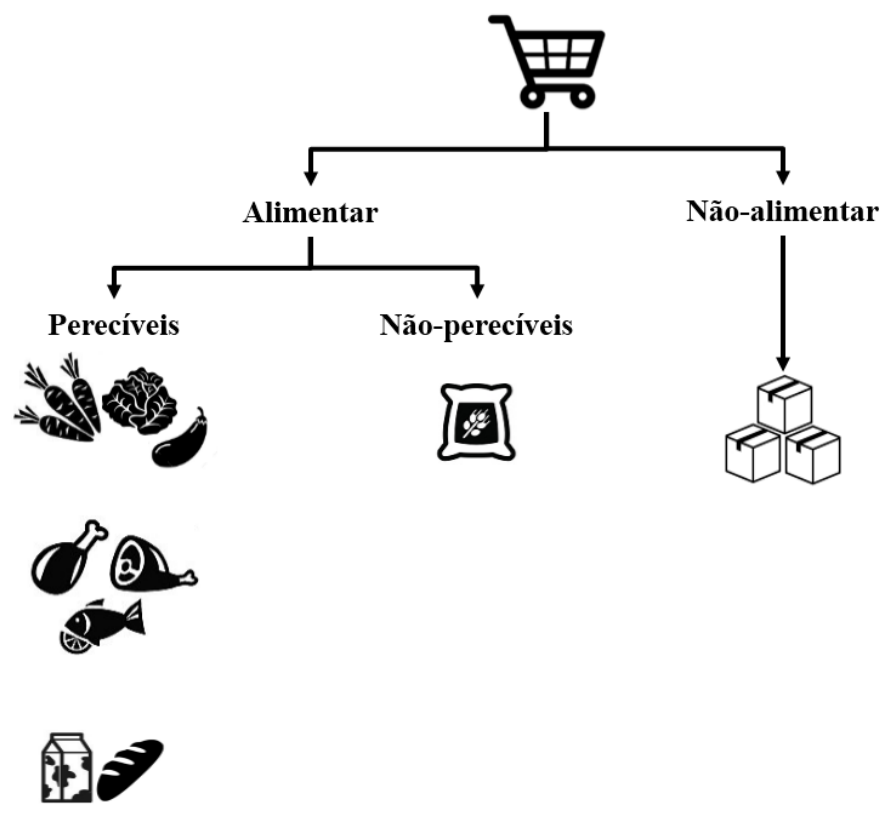

Figura 12: Classificação dos insumos adquiridos pela empresa X. Fonte: Elaborado pelo autor (2019).

As operações são divididas em Delivery e In Company.

A divisão Delivery (Figura 13) é responsável pela produção das refeições na matriz e entrega das refeições prontas para consumo nos pontos de consumo, e os principais clientes são empresas e instituições os quais não possuem espaço físico para instalação de uma cozinha, não tem mão de obra suficiente e que querem praticidade durante as refeições.

A operação se inicia com a aquisição dos insumos alimentares do fornecedor (1) os quais são entregues na matriz (2). Nas dependências da matriz são realizados todos os processos produtivos para o preparo das refeições, como o descascamento de legumes, higienização de verduras, corte de carnes, preparo de sobremesas, cocção dos alimentos por ar quente seco e/ou úmido e envase das preparações em embalagens individuais prontas para consumo.

Depois de preparado as refeições, elas são transportadas (3) em veículos apropriados para o acondicionamento de alimentos, e por fim entregues aos clientes (4). 


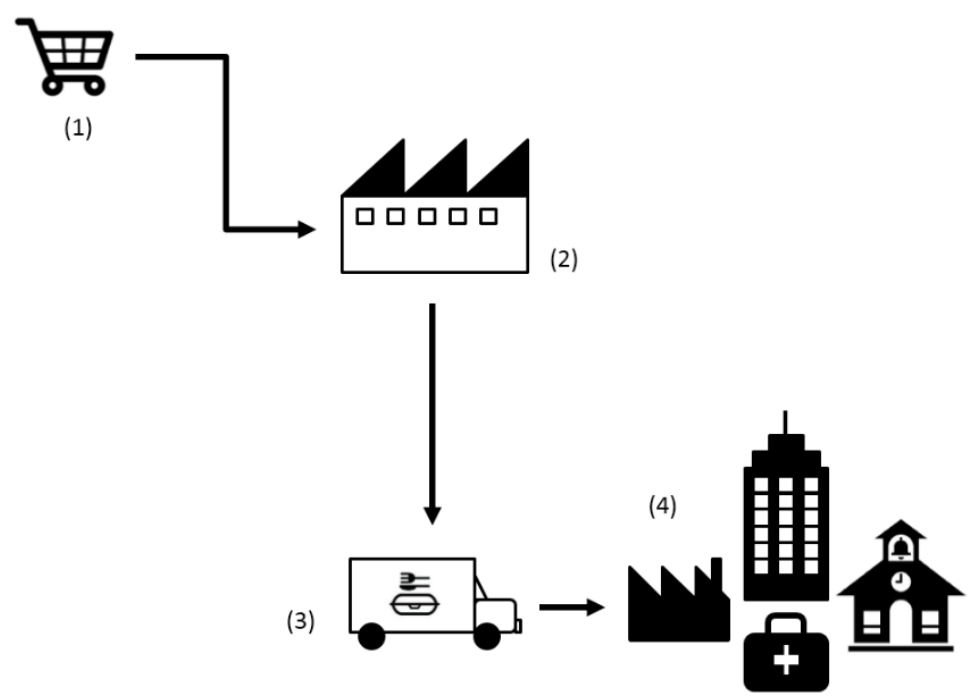

Figura 13: Operação da divisão Delivery da empresa X. Fonte: Elaborado pelo autor (2019).

A divisão In Company (Figura 14) trata-se de cozinhas instaladas nas dependências do cliente onde toda cadeia de fornecimento, produção e entrega é feita no próprio local de consumo. Os principais clientes dessa modalidade são hospitais, unidades básicas de saúde, unidades de pronto atendimento e centros de atendimento psicossociais.

A operação se inicia pela aquisição dos insumos alimentares os quais podem ser distribuídos em três partes, sendo que do fornecedor (1) até o centro de distribuição (2) são enviados os insumos alimentares não-perecíveis e os não-alimentares. Para os insumos alimentares perecíveis, existem duas opções de envio, dependendo da solução demandada pelo cliente. No caso de envio direto do fornecedor (1) para o cliente (4), os insumos são todos processados na cozinha do cliente. Entretanto, em alguns casos, o cliente contrata uma solução customizada na qual adquire vegetais minimamente processados para otimizar o espaço das câmaras frias e refrigeradores, e/ou solicita uma solução diferenciada como cardápios variados para um mesmo dia, exigindo que muitas preparações sejam produzidas na matriz (3) e somente finalizadas no cliente (4). 


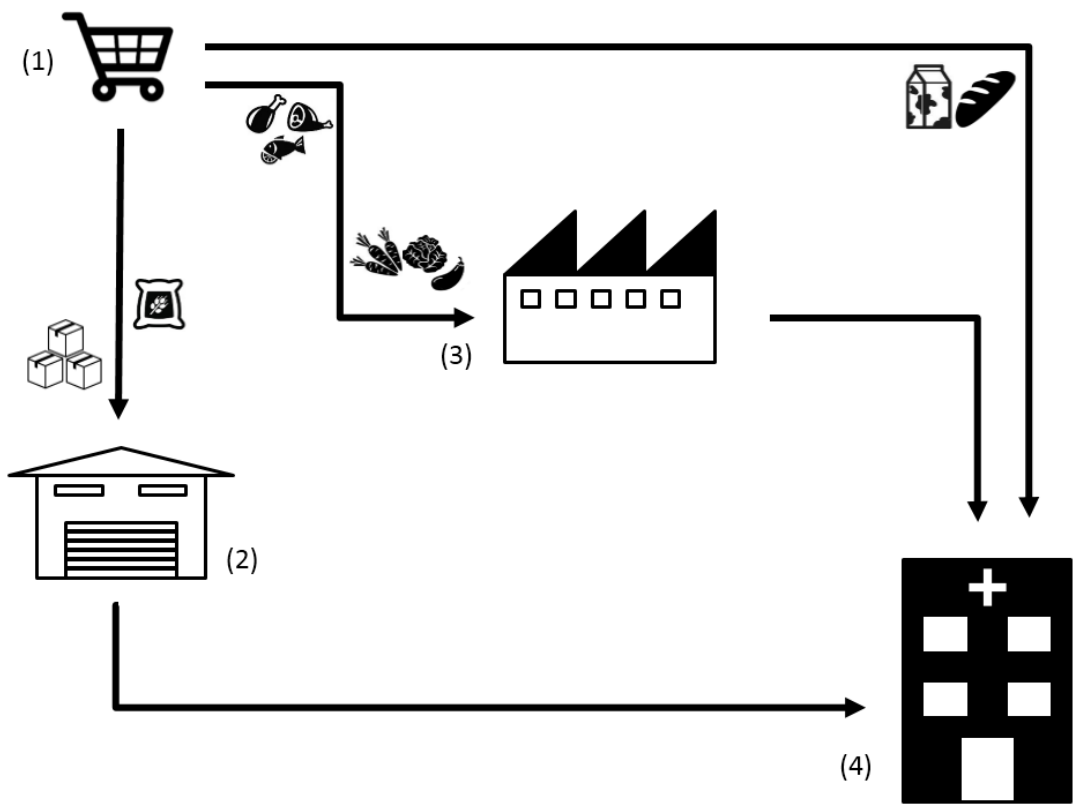

Figura 14: Operação da divisão In Company da empresa X.

Fonte: Elaborado pelo autor (2019).

Outras soluções solicitadas pelos clientes abrangem tanto a preparação das refeições na matriz como na cozinha do cliente. Nesses casos, há uma mescla entre as operações Delivery e In Company, aumentando assim a complexidade do desenho da solução. Essa mescla geralmente ocorre quando um cliente hospitalar necessita que sejam fornecidas todas as refeições do dia (desjejum, colação, almoço, merenda, jantar e ceia), mas não possuem espaço físico suficiente para alocar uma cozinha.

Quando a demanda exige soluções mais complexas, faz-se necessário o uso de processos pouco convencionais (Figura 15) como o Processamento Mínimo de Vegetais (PMV) e o Cook \& Chill (CC). Ambos contribuem para uma maior qualidade final do produto, necessitando assim de investimentos em tecnologia, pois são necessários equipamentos específicos para cada processo.

O PMV consiste em selecionar, cortar, descascar, higienizar, fracionar e acondicionar os vegetais em embalagens dotadas ou não de atmosfera modificada ou controlada e que devem ser mantidos sob refrigeração (ALVARENGA, 2011 apud FARIA; SILVA, 2016). Dessa forma, torna-se possível manter o padrão dos vegetais oferecidos nas unidades In Company. No caso da empresa X, a produção de vegetais minimamente processados tem como premissas reduzir o desperdício, utilizar os recursos de forma eficiente, agregar valor ao produto e reduzir custos operacionais, trazendo ganhos em todos os aspectos da sustentabilidade. 
O processo $\mathrm{CC}$ consiste na cocção dos alimentos seguidos de resfriamento rápido (AHMED et al, 2015). Nesse processo, o alimento está quase pronto para consumo necessitando apenas de regeneração (aquecimento) antes de servir.

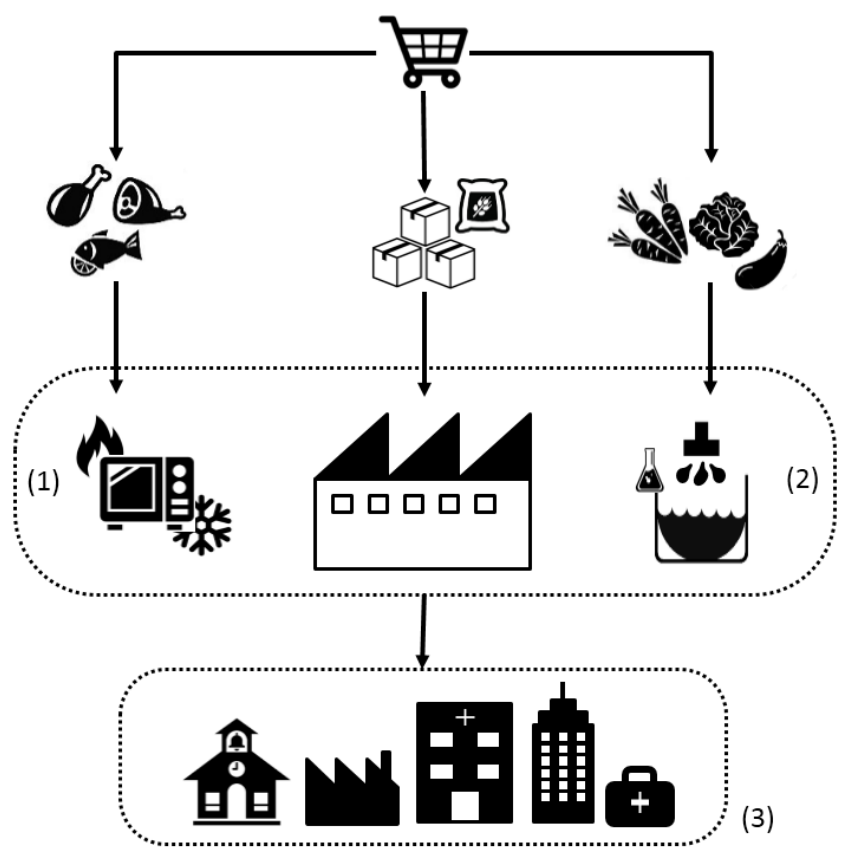

Figura 15: Operação dos processos PMV e CC realizadas na matriz.

Fonte: Elaborado pelo autor (2019).

\subsubsection{COLETA DE DADOS}

A coleta de dados ocorreu em 3 momentos

1. A primeira foi realizada para conhecer os detalhes das operações para a descrição do objeto de pesquisa, as estratégias da empresa e os indicadores aplicáveis ao trabalho de pesquisa baseado nos indicadores estudados na seção 2.3 utilizados para construção do modelo de pesquisa.

2. Com essas informações, a segunda entrevista foi para validar os cenários de simulação e coletar os dados dos indicadores selecionados para cada cenário.

3. Por fim, na terceira entrevista foi para validar os resultados obtidos em simulação e mostrar os resultados dos cenários.

Todas as entrevistas foram realizadas com o gerente geral de operações que é responsável pelas operações Delivery, In Company e PMV. O autor, por trabalhar na área 
de processos e controle da empresa X, também tinha conhecimento técnico para apoiar no fornecimento de dados.

O gerente geral de operações explicou que a atual estratégia foi a introdução de uma célula produtora de vegetais minimamente processados. Já consolidado a 4 anos, a linha de PMV produz somente para o consumo da produção interna de refeições que são servidos na divisão Delivery, mas existe uma demanda para se produzir os VMP para a divisão In Company.

Com essa demanda, o gerente contou que a próxima ação seria a produção de VMP para preparação e consumo nas unidades hospitalares. $\mathrm{O}$ cliente quer um produto diferenciado e com maior valor agregado. Alguns testes foram realizados, mas nada representativo para tomada de decisão.

$\mathrm{O}$ gestor relatou que se as unidades hospitalares forem abastecidas com os VMP com resultado satisfatório e o cliente aprovar o produto, a empresa tem como estratégia a longo prazo a venda dos VMP no mercado varejista.

Com relação aos aspectos da sustentabilidade, a empresa não possui alguns indicadores (Tabela 3) por não serem aplicáveis e/ou porque a informação não está disponível para acesso. 
Tabela 3: Lista de indicadores não selecionados.

\begin{tabular}{|c|c|c|}
\hline \multicolumn{2}{|r|}{ Indicador não selecionado } & Evidência relatada \\
\hline \multirow{4}{*}{ Ambiental } & $i_{5}=$ Emissão de poluentes & $\begin{array}{l}\text { A empresa não possui controle nenhum } \\
\text { de emissão de poluentes. }\end{array}$ \\
\hline & $i_{6}=\begin{array}{l}\text { Utilização de fontes } \\
\text { renováveis de energia }\end{array}$ & $\begin{array}{l}\text { A empresa não faz uso de fontes } \\
\text { renováveis de energia. }\end{array}$ \\
\hline & $i_{8}=$ Quantidade de resíduos & $\begin{array}{l}\text { Evidenciou-se uma primeira versão do } \\
\text { manual PGR (Programa de Gestão de } \\
\text { Resíduos) de uma empresa terceirizada } \\
\text { para realizar a gestão de resíduos da } \\
\text { empresa, mas ainda estava em } \\
\text { implantação, então não havia evidência } \\
\text { de indicadores de controle da quantidade } \\
\text { de resíduos gerados na empresa. }\end{array}$ \\
\hline & $i_{10}=$ Qualidade & $\begin{array}{l}\text { A empresa relata que a potabilidade da } \\
\text { água é pré requisito para manter as } \\
\text { operações produtivas, portanto não } \\
\text { considera como indicador de controle. }\end{array}$ \\
\hline \multirow[t]{3}{*}{ Econômico } & $i_{11}=$ Lucro & $\begin{array}{l}\text { O lucro da empresa não pode ser } \\
\text { divulgado, mas o resultado operacional, } \\
\text { já contemplado no modelo, será o } \\
\text { indicador chave para compararmos os } \\
\text { cenários. }\end{array}$ \\
\hline & $i_{12}=$ Custo de inventário & Informação que não pode ser divulgada. \\
\hline & $i_{19}=\begin{array}{l}\text { Tempo de espera do } \\
\text { consumidor }\end{array}$ & Não há registro dessa informação. \\
\hline
\end{tabular}

Fonte: Elaborado pelo autor (2019).

\subsubsection{VALIDAÇÃO DOS CENÁRIOS DE SIMULAÇÃO}

Após a seleção dos indicadores (Tabela 4), a descrição deles foi realizada de acordo com as informações obtidas em entrevista com o gerente. 
Tabela 4: Lista de indicadores de desempenho da sustentabilidade.

\begin{tabular}{|c|c|c|c|}
\hline Dimensão & Indicador & Descrição relatada & $\begin{array}{c}\text { Unidade de } \\
\text { medida }\end{array}$ \\
\hline \multirow{6}{*}{ Ambiental } & $i_{1}=$ Desperdício & $\begin{array}{l}\text { Quantidade de alimento pronto } \\
\text { para consumo que sobra e é } \\
\text { descartado }\end{array}$ & Quilos/mês \\
\hline & $i_{2}=\begin{array}{l}\text { Consumo de } \\
\text { água }\end{array}$ & $\begin{array}{l}\text { Volume de água utilizado em } \\
\text { produção e/ou serviço }\end{array}$ & Litros/mês \\
\hline & $i_{3}=\begin{array}{l}\text { Consumo de } \\
\text { energia } \\
\text { elétrica }\end{array}$ & $\begin{array}{l}\text { Quantidade de energia } \\
\text { utilizada em produção e/ou } \\
\text { serviço }\end{array}$ & Kwatt.hora/mês \\
\hline & $i_{4}=\begin{array}{l}\text { Consumo de } \\
\text { combustível }\end{array}$ & $\begin{array}{l}\text { Quantidade de combustível } \\
\text { utilizada em transporte }\end{array}$ & Litros/mês \\
\hline & $i_{7}=\begin{array}{l}\text { Uso de } \\
\text { materiais }\end{array}$ & $\begin{array}{l}\text { Quantidade de matéria-prima } \\
\text { utilizada em produção }\end{array}$ & Quilos/mês \\
\hline & $i_{9}=\begin{array}{l}\text { Uso de } \\
\text { substância } \\
\text { restritas }\end{array}$ & $\begin{array}{l}\text { Quantidade de substâncias } \\
\text { restritas utilizada em produção } \\
\text { e/ou serviço }\end{array}$ & Litros/mês \\
\hline \multirow{7}{*}{ Econômico } & $i_{13}=\begin{array}{l}\text { Custo de mão } \\
\text { de obra }\end{array}$ & $\begin{array}{l}\text { Valor gasto com mão de obra } \\
\text { em produção e/ou serviço }\end{array}$ & Reais/mês \\
\hline & $i_{14}=\begin{array}{l}\text { Custo de } \\
\text { materiais }\end{array}$ & $\begin{array}{l}\text { Valor gasto com matéria-prima } \\
\text { para produção e/ou serviço }\end{array}$ & Reais/mês \\
\hline & $i_{15}=\begin{array}{l}\text { Volume de } \\
\text { produção }\end{array}$ & $\begin{array}{l}\text { Volume de produto produzido } \\
\text { em produção }\end{array}$ & Quilos/mês \\
\hline & $i_{16}=$ Produtividade & Volume de produção por hora & Quilos/hora \\
\hline & $i_{17}=\begin{array}{l}\text { Custo de } \\
\text { investimento }\end{array}$ & $\begin{array}{l}\text { Valor gasto em investimentos } \\
\text { que atendam às demandas } \\
\text { estratégicas }\end{array}$ & Reais/mês \\
\hline & $i_{18}=\begin{array}{l}\text { Tempo de } \\
\text { operação }\end{array}$ & $\begin{array}{l}\text { Tempo utilizado para a } \\
\text { execução e entrega do produto } \\
\text { acabado }\end{array}$ & Horas/mês \\
\hline & $i_{20}=\begin{array}{l}\text { Quantidade } \\
\text { de clientes } \\
\text { atendidos }\end{array}$ & $\begin{array}{l}\text { Quantidade de refeições } \\
\text { servidas }\end{array}$ & Unidade/mês \\
\hline \multirow{4}{*}{ Social } & $i_{21}=\begin{array}{l}\text { Horas de } \\
\text { trabalho }\end{array}$ & $\begin{array}{l}\text { Tempo utilizado para a } \\
\text { execução do trabalho }\end{array}$ & Horas/mês \\
\hline & $i_{22}=\begin{array}{l}\text { Saúde dos } \\
\text { trabalhadores }\end{array}$ & $\begin{array}{l}\text { Valor gasto para garantir a } \\
\text { saúde dos trabalhadores }\end{array}$ & Reais/mês \\
\hline & $i_{23}=\begin{array}{l}\text { Segurança do } \\
\text { trabalhador }\end{array}$ & $\begin{array}{l}\text { Valor gasto para garantir a } \\
\text { segurança dos trabalhadores }\end{array}$ & Reais/mês \\
\hline & $i_{24}=\begin{array}{l}\text { Treinamento } \\
\text { e educação }\end{array}$ & $\begin{array}{l}\text { Valor gasto para capacitação } \\
\text { dos trabalhadores }\end{array}$ & Reais/mês \\
\hline
\end{tabular}

Fonte: Elaborado pelo autor (2019). 
Com as informações necessárias para a construção dos cenários, elaborou-se 3 cenários de simulação alinhados às estratégias reportadas pelo gerente geral de operações.

A figura 16 retrata o funcionamento das operações quando a produção de VMP era somente utilizado na produção interna, limitando-se para a operação Delivery. Neste cenário temos todas informações necessárias para a construção e parametrização da simulação.

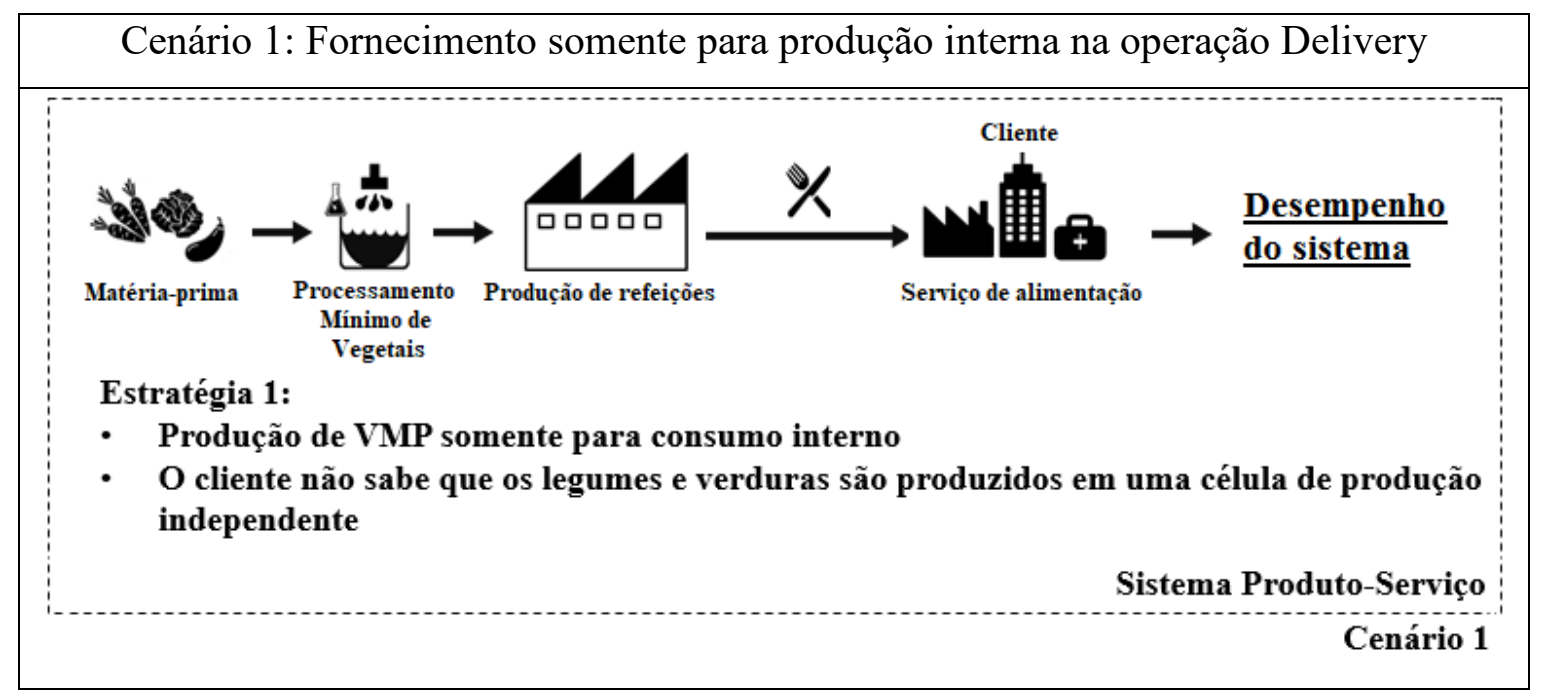

Figura 16: Cenário 1.

Fonte: Elaborado pelo autor (2019).

No segundo cenário (Figura 17) as operações de fornecimento de VMP começam a se descentralizar e a operação In Company passa a receber em suas unidades os vegetais processados. Os clientes das unidades hospitalares observam que a refeição que eles consomem passa a ter um nível de qualidade percebida maior, pois entendem que o VMP já passou por um cuidado maior na seleção e higienização da matéria-prima. Além disso a produção de refeições nas unidades passa a ser otimizado, porque a mão de obra local poderá dispor de mais tempo com outras atividades na cozinha, por exemplo a finalização dos pratos. 


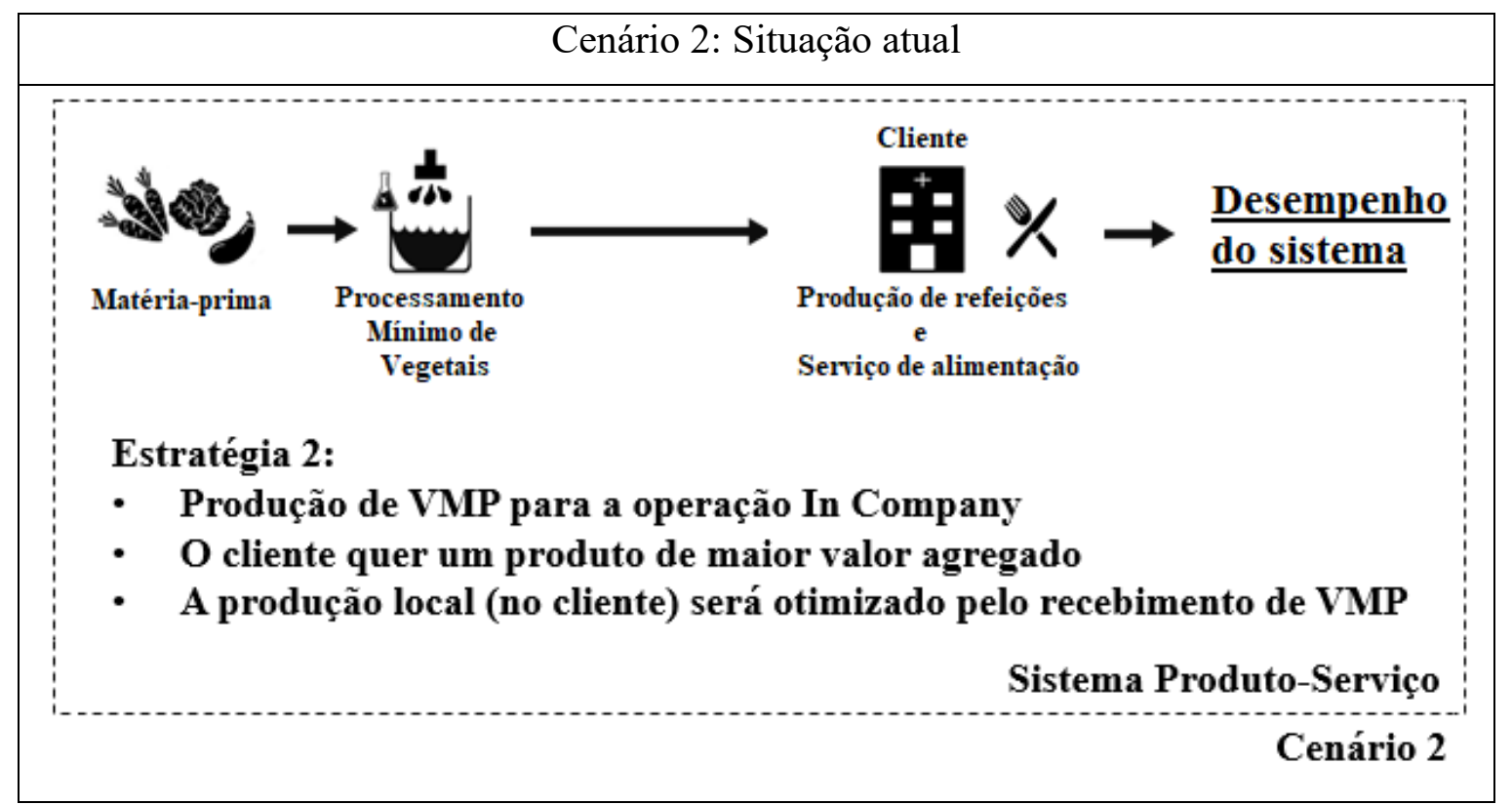

Figura 17: Cenário 2.

Fonte: Elaborado pelo autor (2019).

O último cenário (Figura 18) ainda não é conhecido, mas foi estrategicamente estimado pelo gerente da empresa. E nele a produção de VMP não atenderia somente as operações internas da empresa, mas também o mercado externo como supermercados e hipermercados.

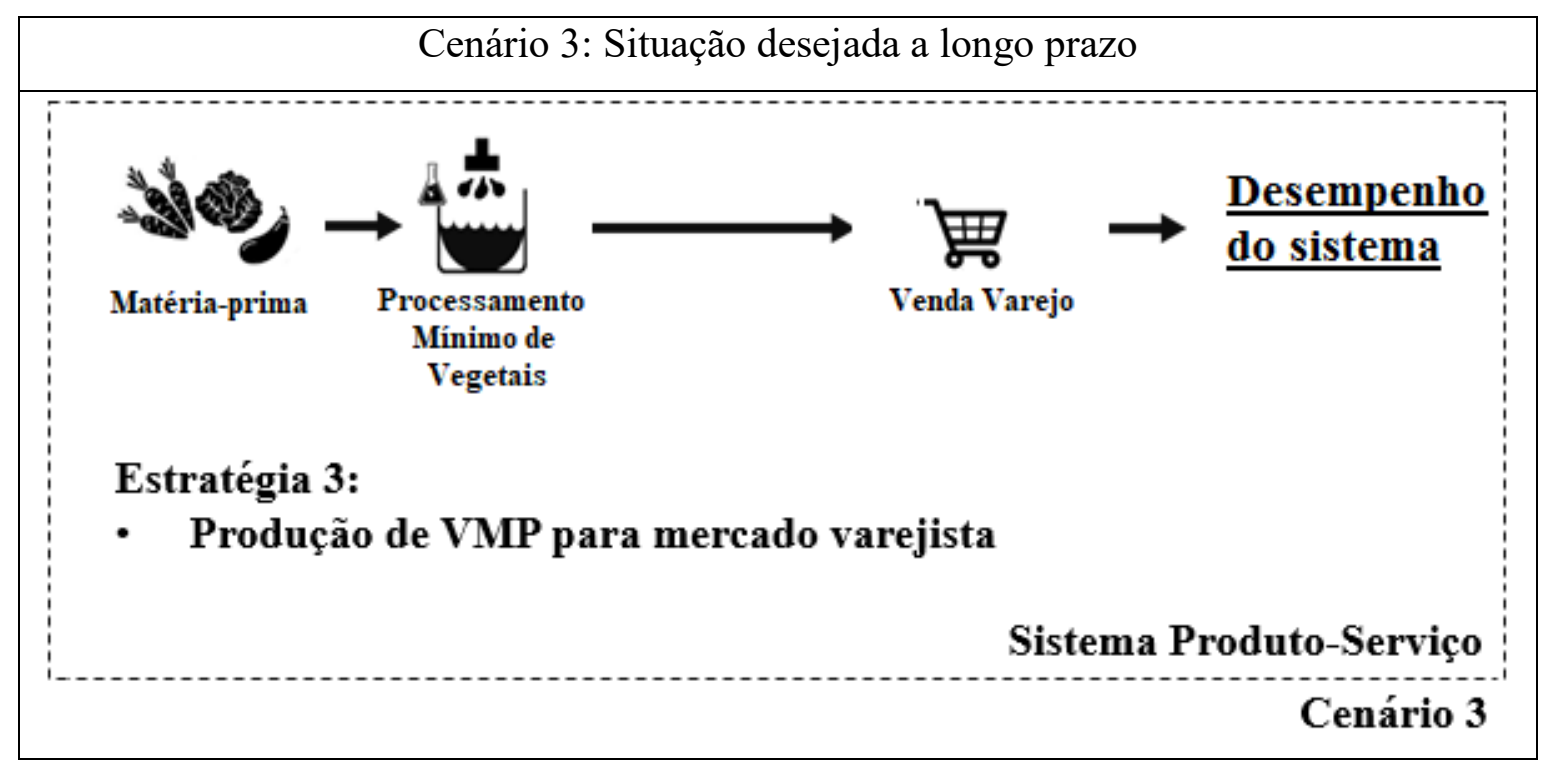

Figura 18: Cenário 3.

Fonte: Elaborado pelo autor (2019).

A proposta é a de utilizar a ferramenta de simulação para realizar as análises dos cenários. Alguns autores como Bianchi et al (2009), Kuo (2011), Alix \& Zacharewicz 
(2012), Wrasse et al (2015) e Weidmann et al (2015) realizaram pesquisas utilizando a simulação como ferramenta de apoio no estudo do PSS.

Existe uma variedade de metodologias para PSS's as quais podem ser encontradas na literatura e aplicadas aos diversos sistemas (BEUREN et al, 2013), mas Weidmann et al (2015), Moon (2016) e Rondini et al (2017) relataram a importância do uso da modelagem e simulação tanto para retratar o comportamento do sistema mas também para auxiliar nos processos de tomada de decisão de acordo com os cenários analisados.

No próximo capítulo são mostrados os cenários construídos para a execução da simulação, o cálculo dos indicadores e a validação dos cenários do modelo. Para a construção dos cenários de simulação, utilizou-se o software ProModel 2016 versão estudante.

\section{RESULTADOS E DISCUSSÕES}

\subsubsection{MODELO DE SIMULAÇÃO}

Cenário 1

O cenário 1 (Figura 19) retratou como a empresa operava de 2015 até 2017 e os VMP ainda não eram utilizados nas unidades hospitalares. Os vegetais eram entregues diretamente às unidades hospitalares sem passar por nenhum processamento, ou seja, cada unidade era responsável por higienizar e cortar antes do cozimento dos alimentos.

Neste cenário gerava-se muitos resíduos sólidos como cascas e partes avariadas impróprias para consumo. Somente a produção interna fazia uso dos VMP para a elaboração das preparações dos clientes da operação Delivery. Naquela época, relatou-se que a geração de resíduos no processamento mínimo parecia ser menor, proporcionalmente, em relação aos resíduos gerados nas unidades da operação In Company. 


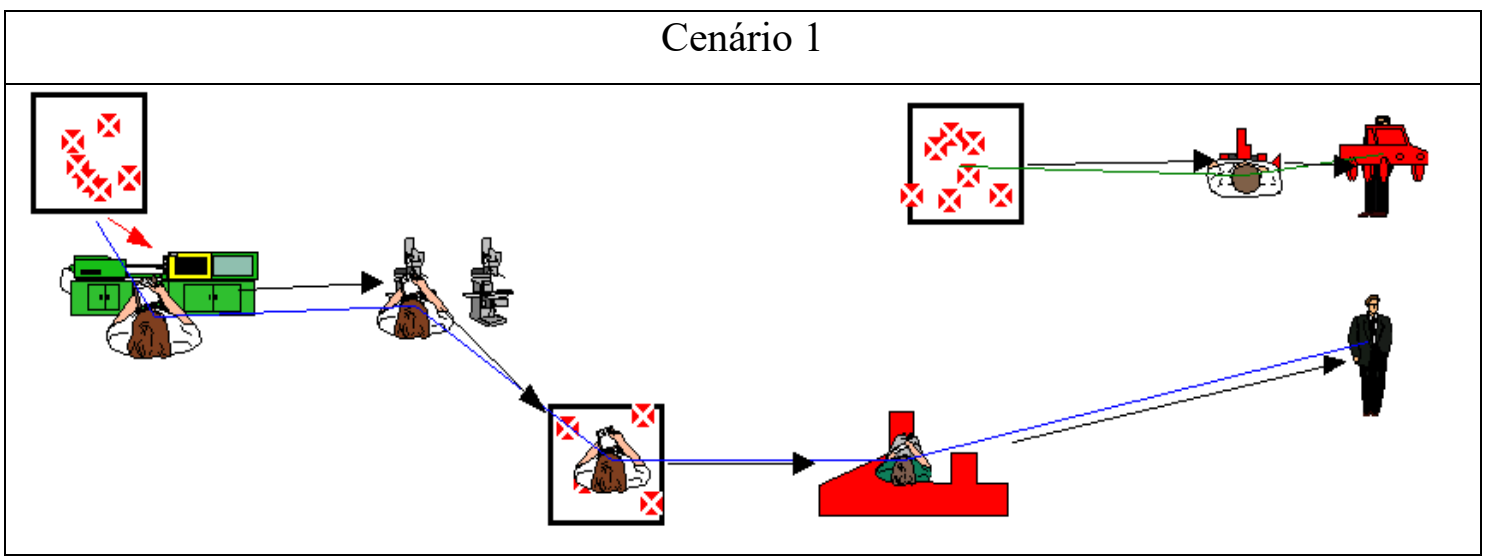

Figura 19: Estrutura de simulação construída no ProModel ilustrando o cenário 1.

Cenário 2

Diante daquele cenário, optou-se por centralizar a produção de VMP na célula produtora localizada na matriz e começar a fornecer para todos os clientes ativos (Figura 20). Então os clientes In Company passaram a receber VMP em suas unidades hospitalares gerando valor a eles. A produção em cada cozinha descentralizada foi otimizada, reduzindo-se a carga de resíduos sólidos.

A empresa continua operando neste cenário, mas tem dificuldades de atendimento, pois ainda não consegue fornecer para todas unidades, abrangendo aproximadamente $10 \%$ da operação In Company.

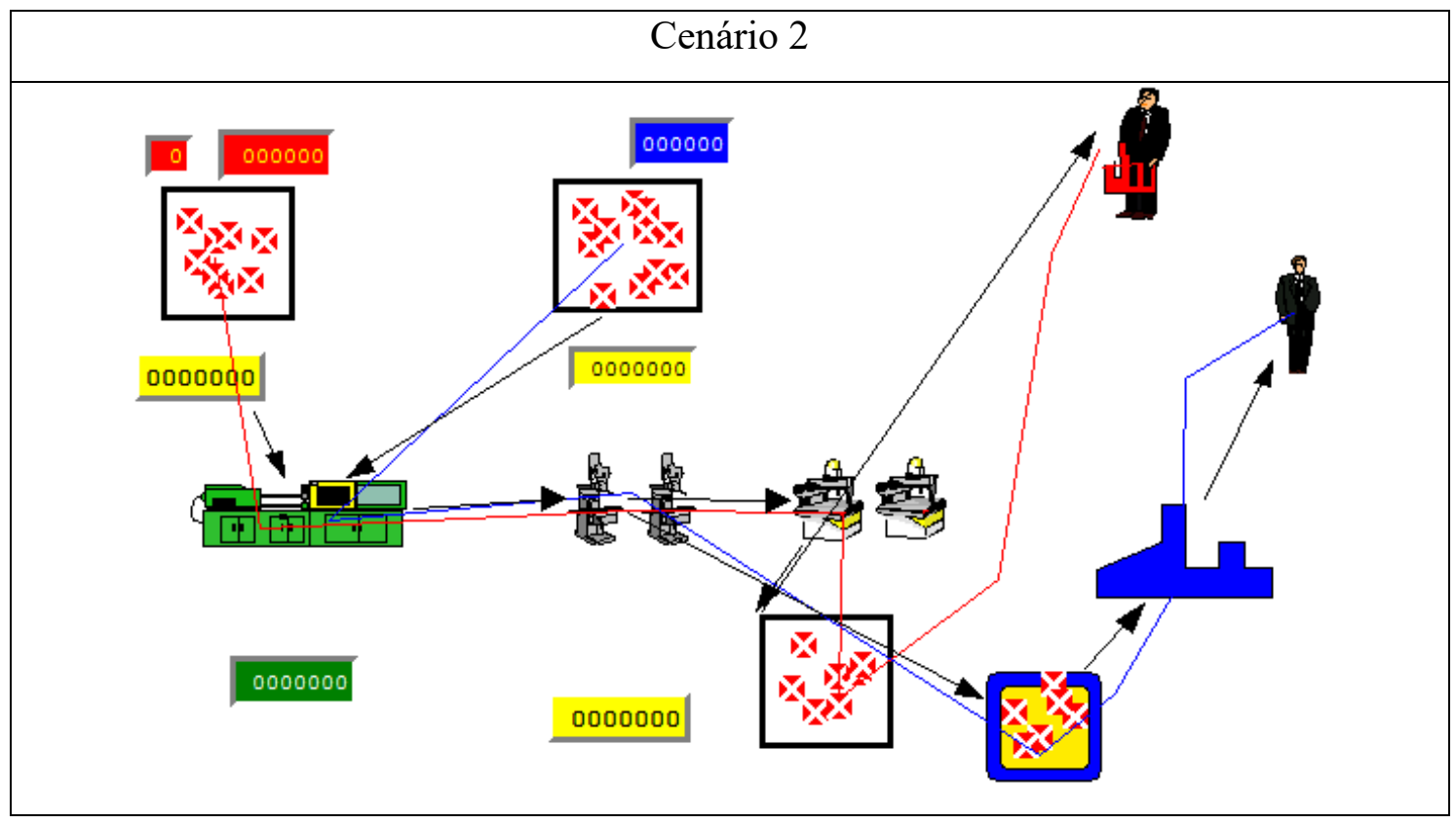

Figura 20: Estrutura de simulação construída no ProModel ilustrando o cenário 2. 


\section{Cenário 3}

Para o futuro, pretende-se aumentar o fornecimento de VMP para mais clientes da operação In Company e Delivery, bem como a abertura de uma nova frente de fornecimento (Figura 21). Trata-se de produzir e vender VMP para o consumidor final. Além de atender a demanda do mercado de VMP e dos potenciais clientes da empresa, o ganho sustentável será maior, pois espera-se manter os indicadores em níveis semelhantes ao cenário 2 mesmo havendo um aumento abrupto da demanda do cenário 3 .

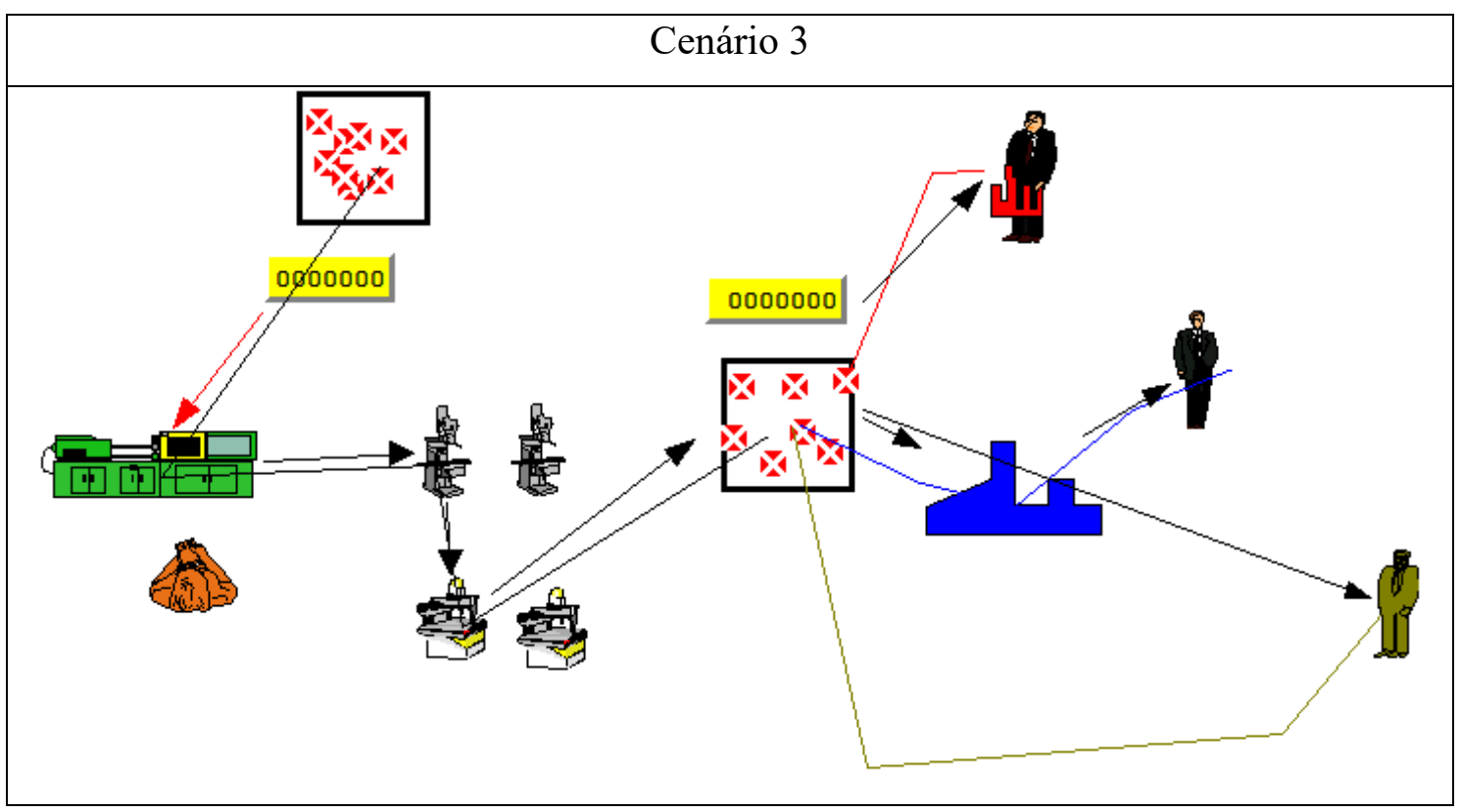

Figura 21: Estrutura de simulação construída no ProModel ilustrando o cenário 3.

\subsubsection{RESULTADOS OBTIDOS}

As considerações e parametrizações dos três cenários foram as de que se manteria a capacidade de armazenamento de vegetais e a quantidade de mão de obra produtiva. $\mathrm{O}$ gerente propôs como cenário mais provável apenas a contratação de mais veículos para transportar os vegetais minimamente processados.

Ele acreditou que seria possível alcançar maior eficiência da mão de obra e redução dos níveis de desperdício para ser capaz de suportar a demanda futura. 
Os resultados do cenário 3 indicaram que o sistema não suportará o crescimento de demanda sem sofrer adequações (Tabela 5)

Tabela 5: Resultado da simulação antes da alteração do cenário 3.

\begin{tabular}{|c|c|c|c|}
\hline & Cenário 1 & Cenário 2 & Cenário 3 \\
\hline $\begin{array}{c}\text { Quantidade total de } \\
\text { VMP produzido } \\
(\mathrm{Kg} / \mathrm{mês})\end{array}$ & 42.164 & 45.598 & 45.000 \\
\hline
\end{tabular}

Ao validar os resultados de VMP produzidos nos três cenários, o gerente percebeu que as capacidades e recursos hoje implantados não serão suficientes. Isso já era percebido pelo resultado da simulação do cenário 2, pois este resultado é apenas $30 \%$ de toda demanda da operação In Company.

Portanto, propôs-se uma nova simulação do cenário 3 com o intuito de adequar as expectativas da empresa ao modelo de simulação.

Com esses novos dados, simulou-se novamente o cenário 3 e obteve-se como resultado o atendimento parcial das novas demandas (Tabela 6). Entretanto, o impacto que essa mudança causará nas dimensões da sustentabilidade do sistema não serão satisfatórias.

Tabela 6: Resultado da simulação considerando novos dados para o cenário 3.

\begin{tabular}{|c|c|c|c|}
\hline & Cenário 1 & Cenário 2 & Cenário 3 \\
\hline $\begin{array}{c}\text { Quantidade total de } \\
\text { VMP produzido } \\
(\mathrm{Kg} / \mathrm{mês})\end{array}$ & 42.164 & 45.598 & 60.800 \\
\hline
\end{tabular}

Os parâmetros utilizados para rodar as simulações no ProModel e gerar os resultados das tabelas 5 e 6 estão em anexo (ANEXO A, ANEXO B e ANEXO C).

\subsubsection{COMPARATIVO DOS CENÁRIOS}

Transição do cenário 1 para o cenário 2

A transição do cenário 1 para o 2 fez com que parte dos estoques de matéria-prima das cinco unidades da operação In Company fossem transferidos para a matriz da 
empresa. A matriz da empresa possui capacidade para armazenar $30.000 \mathrm{Kg}$ de vegetais, sendo que nessa transição houve o compartilhamento do espaço da câmara fria entre as duas operações.

Com a produção centralizada, contratou-se transporte para realizar o envio dos VMP para as unidades da operação In Company, acarretando não somente em aumento de despesa mas também na emissão de gases poluentes advindos dos veículos contratados.

Em contrapartida, identificou-se alguns ganhos nessa transição como o aumento no rendimento de processo, pois a etapa de corte dos vegetais realizada no cenário anterior gerava um rendimento médio global de aproximadamente $85 \%$. A célula de produção é capaz de atingir em torno de $91 \%$ de rendimento, reduzindo a carga de matéria sólida orgânica.

A redução do consumo de água e energia são potenciais ganhos, porque reduziuse parcialmente o consumo em algumas unidades hospitalares e passaram a ser centralizados na matriz da empresa.

Em análise conjunta com o gerente, estimou-se que se o cenário 2 já fosse capaz de atender a demanda, o conjunto das unidades somariam uma economia aproximada de 36.000 litros por mês de água utilizada para higienização dos vegetais e $10.800 \mathrm{kWatt}$ de consumo de energia pelo armazenamento dos vegetais em câmaras frias ou refrigeradores domésticos.

Transição do cenário 2 para o cenário 3

O gerente geral relatou que essa transição se faz necessária para atender os objetivos estratégicos da empresa, pois o mercado de VMP é promissor não somente para otimizar as operações internas mas também para o mercado consumidor que sinaliza interesse por preparações mais saudáveis. A empresa busca alcançar um crescimento de mais clientes da operação In Company e Delivery, exigindo maior produção, e também clientes como supermercados e hipermercados da região.

Para que essa mudança ocorra, estima-se um investimento na compra de equipamentos, na contratação de mais trabalhadores e na construção de câmara fria para armazenagem.

Com toda a produção centralizada, acredita-se alcançar um rendimento médio de $92 \%$, pois a mão de obra estaria cada vez mais bem treinada e as negociações com os fornecedores seriam mais assertivas. 


\subsubsection{ANÁLISE DOS INDICADORES E DESEMPENHO DO SISTEMA}

Os indicadores discutidos na revisão bibliográfica e validados no item 3.2 (coleta de dados) indicaram que a evolução dos cenários causou impactos nas dimensões da sustentabilidade.

A variação dos indicadores entre os cenários 1 e 2 não foram significativos em relação ao cenário 3 , porque o sistema atual somente incorporou $30 \%$ da demanda da operação In Company, portanto a discussão dos resultados foi focado no cenário 3.

Para o cenário 3, o gerente geral forneceu estimativa de dados de como a empresa operaria para atender a demanda futura e o cenário mais provável atenderia $74 \%$ de quantidade de VMP produzida.

A redução do desperdício foi devido a uma negociação com novos fornecedores de hortifrútis que apresentaram uma matéria-prima de melhor qualidade e no trabalho constante de gestão operacional que treina os funcionários a atingirem menores níveis de perdas em processo. Os resíduos gerados em processo, na cozinha do cliente, são descartados em local refrigerado nas dependências do cliente e o mesmo é responsável por contratar uma empresa especializada para a coleta final.

Na dimensão ambiental (Tabela 7), o aumento do consumo de combustível a princípio parece ser inevitável, pois a expansão de clientes e operações fará com que a empresa contrate mais veículos para transportar os VMP, não havendo perspectivas de soluções alternativas que reduzam o consumo e emissão de poluentes. O gerente pontuou que idealiza a utilização de veículos elétricos no futuro. 
Tabela 7: Comparativo dos indicadores ambientais.

\begin{tabular}{|c|c|c|c|c|c|}
\hline Dimensão & Indicador & $\begin{array}{l}\text { Unidade de } \\
\text { medida }\end{array}$ & Cenário 1 & $\begin{array}{c}\text { Cenário } \\
2\end{array}$ & $\begin{array}{c}\text { Cenário } \\
3\end{array}$ \\
\hline \multirow{6}{*}{ Ambiental } & $i_{1}=$ Desperdício & Quilos/mês & 7.440 & 4.509 & 5.280 \\
\hline & $i_{2}=\begin{array}{l}\text { Consumo de } \\
\text { água }\end{array}$ & Litros/mês & 62.300 & 63.000 & 77.000 \\
\hline & $i_{3}=\begin{array}{l}\text { Consumo de } \\
\text { energia } \\
\text { elétrica }\end{array}$ & Kwatt.hora/mês & 10.600 & 11.000 & 13.500 \\
\hline & $i_{4}=\begin{array}{l}\text { Consumo de } \\
\text { combustível }\end{array}$ & Litros/mês & 5.400 & 5.640 & 5880 \\
\hline & $i_{7}=\begin{array}{l}\text { Uso de } \\
\text { materiais }\end{array}$ & Quilos/mês & 49.600 & 50.100 & 66.000 \\
\hline & $\begin{aligned} & \text { Uso de } \\
& i_{9}= \text { substância } \\
& \text { restritas }\end{aligned}$ & Litros/mês & 18 & 18 & 25 \\
\hline
\end{tabular}

Os resultados coletados para o indicador de consumo de água devem ser analisados levando em consideração algumas premissas da empresa. Mesmo atendendo somente $30 \%$ da demanda do In Company, o aumento entre os cenários 1 e 2 foi de somente 700 litros por mês, sendo que a economia estimada nas unidades hospitalares era de aproximadamente 36.000 litros por mês. Foi relatado que a empresa possui um sistema de captação de água de poço artesiano o qual não foi informado o volume captado. Diante disto é notável que através desse sistema de captação de água, a empresa possui vantagens em relação à despesa com água da rede pública. O mesmo vale para o aumento estimado para o cenário 3 .

Assim como o aumento do consumo de combustível, o consumo de energia elétrica também aumentará conforme a empresa investe em novos equipamentos para aumentar a capacidade do sistema. $\mathrm{O}$ gerente demonstrou pouco interesse neste indicador porque ele acredita que a variedade de produtos alimentícios que dependam da cadeia fria sempre estará em ascensão, portanto a necessidade de câmaras frias para conservação produtos resfriados e/ou congelados não permitirá a redução do consumo energético

A princípio o aumento do uso de substâncias restritas no cenário 3 não causaria problemas ambientais pois o gerente relatou que a carga de efluentes despejados na rede pública de água e esgoto atende o limites do órgão fiscalizador da região. 
Na dimensão econômica (Tabela 8), o custo da mão de obra foi aumentando do cenário 1 para o 2 conforme a necessidade de motoristas para transportar os produtos para os clientes e unidades, ou seja, a célula produtiva permaneceu com o mesmo quadro de trabalhadores. Como identificou-se que o sistema do cenário 3 precisava de um redimensionamento, o quadro de mão de obra foi acrescentado de mais 8 recursos para compor a célula de produção, além de mais motoristas.

Tabela 8: Comparativo dos indicadores econômicos.

\begin{tabular}{|c|c|c|c|c|c|}
\hline Dimensão & Indicador & $\begin{array}{l}\text { Unidade de } \\
\text { medida }\end{array}$ & $\begin{array}{c}\text { Cenário } \\
1\end{array}$ & $\begin{array}{c}\text { Cenário } \\
2\end{array}$ & $\begin{array}{c}\text { Cenário } \\
3\end{array}$ \\
\hline \multirow{7}{*}{ Econômico } & $i_{13}=\begin{array}{l}\text { Custo de mão } \\
\text { de obra }\end{array}$ & Reais/mês & 140.000 & 150.000 & 180.000 \\
\hline & $i_{14}=\begin{array}{l}\text { Custo de } \\
\text { materiais }\end{array}$ & Reais/mês & 94.000 & 95.000 & 125.150 \\
\hline & $i_{15}=\begin{array}{l}\text { Volume de } \\
\text { produção }\end{array}$ & Quilos/mês & 42.164 & 45.598 & 60.864 \\
\hline & $i_{16}=$ Produtividade & Quilos/hora & 156 & 169 & 225 \\
\hline & $i_{17}=\begin{array}{l}\text { Custo de } \\
\text { investimento }\end{array}$ & Reais/mês & 1.200 & 1.200 & 5.000 \\
\hline & $i_{18}=\begin{array}{l}\text { Tempo de } \\
\text { operação }\end{array}$ & Horas/mês & 270 & 270 & 270 \\
\hline & $i_{20}=\begin{array}{l}\text { Quantidade } \\
\text { de clientes } \\
\text { atendidos }\end{array}$ & Unidade/mês & 17 & 22 & 32 \\
\hline
\end{tabular}

O custo de materiais, o volume de produção e a produtividade são indicadores que aumentaram proporcionalmente à demanda estimada pela empresa. O volume de produção indica que haverá aumento na geração de resíduos sólidos em produção, mas que poderá ser otimizado pelas ações em relação às metas de desperdício.

Como investimento, a empresa pretende comprar quatro novas embaladoras a vácuo, duas novas cortadoras de vegetais e construir uma câmara fria de armazenagem para suportar o crescimento por mais 3 anos. Esses investimentos acarretarão, a princípio, no aumento de consumo energético.

Deseja-se alcançar uma carteira de 32 clientes ativos para o cenário futuro. $\mathrm{Na}$ discussão dos resultados da simulação, o gerente da empresa está avaliando, a partir deste 
trabalho, um crescimento econômico-financeiro visando o impacto que poderia causar aos indicadores da sustentabilidade, não somente para a manutenção ambiental e bemestar humano como também na visibilidade que a empresa teria perante seus clientes. Ele comentou que um dos intuitos do fornecimento de VMP é mostrar que a empresa tem boas práticas sustentáveis.

Na dimensão social praticamente não houveram variações nos indicadores (Tabela 9) pois o gerente relatou que desde o cenário 1 até o cenário 3 não haveria mudança na carga horária de trabalho bem como alguns benefícios. Para garantir a saúde e segurança dos trabalhadores, a empresa tem como custo principal o benefício de assistência médica e o equipamento de proteção individual, respectivamente. $\mathrm{O}$ gerente relatou que existe uma despesa com ginástica laboral que contribui para a saúde dos trabalhadores.

Tabela 9: Comparativo dos indicadores sociais.

\begin{tabular}{|c|c|c|c|c|c|}
\hline Dimensão & Indicador & $\begin{array}{l}\text { Unidade de } \\
\text { medida }\end{array}$ & $\begin{array}{c}\text { Cenário } \\
1\end{array}$ & $\begin{array}{c}\text { Cenário } \\
2\end{array}$ & $\begin{array}{c}\text { Cenário } \\
3\end{array}$ \\
\hline \multirow{4}{*}{ Social } & $i_{21}=\begin{array}{l}\text { Horas de } \\
\text { trabalho }\end{array}$ & Horas/mês & 220 & 220 & 220 \\
\hline & $i_{22}=\begin{array}{l}\text { Saúde dos } \\
\text { trabalhadores }\end{array}$ & Reais/mês & 1.000 & 1.000 & 1.180 \\
\hline & $i_{23}=\begin{array}{l}\text { Segurança do } \\
\text { trabalhador }\end{array}$ & Reais/mês & 300 & 300 & 350 \\
\hline & $i_{24}=\begin{array}{l}\text { Treinamento } \\
\text { e educação }\end{array}$ & Reais/mês & 50 & 50 & 50 \\
\hline
\end{tabular}

Treinamentos para o desenvolvimento intelectual do trabalhador é quase insignificante diante dos outros gastos, mas vale ressaltar um ponto importante, que os líderes de áreas administrativas indiretas à produção recebem treinamentos periódicos e tem por prática multiplicar o conhecimento adquirido para os demais trabalhadores da empresa. Mas mesmo assim cabe uma atenção especial caso a empresa invista em educação no futuro e medir o retorno disso na produtividade.

Em virtude dos resultados obtidos em simulação dos três cenários, do levantamento de dados dos indicadores para os cenários 1 e 2 , e da estimativa do cenário 3 , entendeuse que 
- Com o aumento da demanda de VMP, como variação:

- Haverá aumento no consumo de combustível, e consequentemente, aumento na emissão de gases poluentes

○ Exigirá um aumento no quadro de mão de obra, tanto os operacionais de produção como os motoristas

- Demandará maior capacidade de equipamentos e armazenamento, necessitando maiores investimentos

- Aumentará o consumo energético o qual fará com que a empresa tenha que buscar novas fontes de geração de energia, como por exemplo, energia solar

Nesse caso, os pontos retratados acima são os indicadores que merecem uma atenção maior, pois demandarão ações imediatas da empresa para, somente assim, atender parte da demanda ideal.

\section{CONCLUSÕES}

Os indicadores avaliados juntamente com o desempenho simulado atenderam o objetivo de avaliar o PSS sob a ótica da sustentabilidade bem como demonstrar as necessidades da empresa. Cada cenário de simulação foi capaz de retratar a capacidade de produzir VMP de acordo com as condições e estratégias adotadas pela empresa.

Os indicadores elencados da literatura e selecionados para análise mostraram em quais pontos do sistema precisam de maior atenção para se alcançar o desempenho desejado.

A simulação foi capaz de mostrar que o sistema não atenderia a demanda dos cenários 2 e 3 e que somente atenderia parcialmente mesmo com as propostas de mudança ditas pelo gestor das operações, ou seja, as estratégias para o futuro que a empresa pretende adotar não poderá ser suportado pelas capacidades hoje utilizadas. Mesmo a empresa acreditando que obtiveram um grande salto do cenário 1 para o cenário 2, ainda está longe de atingir a demanda do cenário 3. Apesar das diferenças de valores dos indicadores ambientais nos primeiros cenários, nota-se que o consumo de água e energia sofreram pouca variação, mas que ainda merecem atenção para o cenário futuro. Mesmo sendo inevitável o maior uso de materiais e a geração de resíduos, entende-se que a empresa continuará agindo sobre a redução de desperdício, conseguindo manter níveis 
menores que as do passado. Com relação as questões sociais, os indicadores não mostraram grandes variações para o futuro, mas cabe ressaltar que a empresa faz bom uso da mão de obra administrativa para ministrar treinamentos internos para as equipes operacionais.

O presente trabalho contribuiu preenchendo uma lacuna de pesquisa no âmbito da utilização de método quantitativo para avaliar um PSS, estudo e uso de indicadores da sustentabilidade e também a relação entre os indicadores e o desempenho do sistema sob os aspectos econômicos, ambientais e sociais.

Sugere-se a continuidade deste trabalho com foco em um cenário ideal que tanto atenda às expectativas da empresa como o desempenho do sistema produto-serviço de modo a satisfazer as dimensões da sustentabilidade. 


\section{REFERENCIAS BIBLIOGRÁFICAS}

Aberc, 2017. <http://www.aberc.com.br/conteudo.asp?IDMenu=18> (acesso: 27-072017).

Abia, 2017. <http://www.abia.org.br/vsn/tmp_2.aspx?id=319\#sthash.mToNi0Ty.dpbs > (acesso: 27-07-2017).

Ahmed, M.;Redmond, E.; Jones, E.; Hewesi, M.; Wingert, A.; El Rab, M.G. Food production and service in UK hospitals. International Journal of Health Care Quality Assurance. Vol. 28, n. 1, pp. 40-54, 2015.

Alix, T.; Zacharewicz, G. Product-service systems scenarios simulation based on GDEVS/HLA: Generalized discrete event specification/high level architecture. Computers in Industry 63, pp. 370-378, 2012.

Alvarenga, A. L. B. Proposta de sistema para a gestão da qualidade e da segurança de vegetais minimamente processados. Tese de doutorado. São Carlos: UFSCar. 2011.

Annarelli, A.; Battistella, C.; Nonino, F. Product service system: A conceptual framework from a systematic review. Journal of Cleaner Production 139, pp. 1011-1032, 2016.

Arcese, G.; Flammini, S.; Lucchetti, M. C.; Martucci, O. Evidence and experience of open sustainability innovation practices in the food sector. Sustainability. N. 7, pp. 80678090, 2015.

Baines, T. S.; Lightfoot, H. W.; Evans, S.; Neely, A.; Greenough, R.; Peppard, J.; Roy, R.; Shehab, E.; Braganza, A.; Tiwari, A.; Alcock, J. R.; Angus, J. P.; Bastl, M.; Cousens, A.; Irving, P.; Johnson, M.; Kingston, J.; Lockett, H.; Martinez, V.; Michele, P.; Tranfield, D.; Walton, I. M.; Wilson, H. State-of-the-art in product-service systems. Journal of Engineering Manufacture. Vol. 221, pp. 1543-1552, 2007.

Baregheh, A.; Rowley, J.; Sambrook, S.; Davies, D. Food sector SMEs and innovation types. British Food Journal. Vol. 114, n. 11, pp. 1640-1653, 2012.

Beuren, F. H.; Ferreira, M. G. G.; Miguel, P. A. C. Product-service systems: a literature review on integrated products and services. Journal of Cleaner Production 47, pp. 222$231,2013$.

Bianchi, N. P.; Evans, S.; Revetria, R.; Tonelli, F. Influencing factors of successful transitions towards product-service systems: a simulation approach. International Journal of Mathematics and Computers in Simulation, issue 1, vol. 3, 2009.

Boehm, M.; Thomas, O. Looking beyond the rim of one's teacup: a multidisciplinary literature review of Product-Service Systems in Information Systems, Business Management, and Engineering \& Design. Journal of Cleaner Production 51, pp. 245-260, 2013. 
Borchadt, M.; Sellitto, M. A.; Pereira, G. M. Sistemas-produto-serviço: Referencial teórico e direções para futuras pesquisas. Revista Produção Online. Vol. 10, n. 4, pp. 837$869,2010$.

Cenci, S. A. Processamento mínimo de frutas e hortaliças: Tecnologia, qualidade e sistemas de embalagem. Rio de Janeiro: Embrapa Agroindústria de Alimentos, 144 p., 2011.

Durugbo, C.; Bankole, O.; Erkoyuncu, J. A.; Tiwari, A.; Alcock, J. R.; Roy, R.; Shehab, E. Product-service systems across industry sectors: Future research needs and challenges. Proceedings of the 2nd CIRP IPS2 Conference, 14-15, pp. 535-542, 2010.

Evans, S.; Partidario, P. J.; Lambert, B. J. Industrialization as a key element of sustainable product-service solutions. Journal of Production Research, 45:18-19, pp. 4225-4246, 2007.

Faria, L. F. F.; Silva, J. E. A. R. Balanceamento de operações em sistemas de processamento mínimo de vegetais: estudos baseados em simulação discreta. 2016.

Fitch, C.; Santo, R. Instituting Change: An overview of institutional food procurement and recommendations for improvement. 2016.

Garcia, F. A. G.; Silva, J. E. A. R.; Borrás, M. A. A.; Fontes, A. R. M.; Ferrarini, C. F. Use of simulation to evaluate a layout proposal for a minimally processed vegetables industry. $22^{\circ}$ International Conference on Production Research. 2013.

Geissler, G. L. Healthy food at work? An examination of a propose catering service concept. Journal of Food Products Marketing, 16:350-360, 2010.

Geng, X.; Chu, X.; Xue, D.; Zhang, Z. A systematic decision-making approach for the optimal product-service system planning. Expert Systems with Applications 38, pp. 11849-11858, 2011.

Ghidelli, C.; Pérez-Gago, M. B. Recent advances in modified atmosphere packaging and edible coatings to maintain quality of fresh-cut fruits and vegetables. Critical Reviews in Food Science and Nutrition. 2016.

Goedkoop, M. J.; van Halen, C. J. G.; te Riele, H. R. M.; Rommens, P. J. M. Product service systems, ecological and economic basics. Product Innovation Technology Management. 1999.

Investesp, 2017. <http://www.investe.sp.gov.br/setores-de-negocios/alimentos/> (acesso: 27-07-2017)

Johns, N.; Edwards, J. S. A.; Hartwell, H. J. Hungry in hospital, well-fed in prison? A comparative analysis of food service systems. Appetite 68, pp.45-50, 2013.

Joore, P.; Tempelman, E. Validation of life cycle economic benefits of partner-based solutions. In: Manzini, E.; Collina, L.; Evans, S.; editors. Solution oriented partnership: how to design industrialised sustainable solutions. Milton Keynes: Oscar Press, 2004. 
Kahraman, C.; Cebeci, U.; Ruan, D. Multi-attribute comparison of catering service companies using fuzzy AHP: The case of Turkey. International Journal of Production Economics 87, pp. 171-184, 2004.

Komoto, H.; Tomiyama, T.; Nagel, M.; Silvester, S.; Brezet, H. Life cycle simulation for analyzing product service systems. IEEE 2B-1-2F. 2005.

Koren, Y.; Heisel, U.; Jovana, F.; Moriwaki, T.; Pritschow, G.; Ulsoy, G.; Van Brussel, H. Reconfigurable manufacturing systems. Annals of the CIRP. Vol. 48/2, 1999.

Krucken, L.; Meroni, A. Building stakeholder networks to develop and deliver productservice-systems: practical experiences on elaborating pro-active materials for communication. Journal of Cleaner Production 14, pp. 1502-1508, 2006.

Kuo, T. C. Simulation of purchase or rental decision-making based on product service system. Int. J. Adv. Manuf. Technol., 52:1239-1249, 2011.

Law, K. M. Y. Airline catering service operation schedule nervousness and collective efficacy on performance: Hong Kong evidence. The Service Industries Journal, 31:6, pp. 959-973, 2011.

Manzini, E. Solution oriented partnership: introduction. In: Manzini, E.; Collina, L.; Evans, S.; editors. Solution oriented partnership: how to design industrialised sustainable solutions. Milton Keynes: Oscar Press, 2004.

Manzini, E.; Vezzoli, C. A strategic design approach to develop sustainable product service systems: examples taken from the 'environmentally friendly innovation' Italian prize. Journal of Cleaner Production 11, pp. 851-857, 2003.

Mo, J. P. T. Performance assessment of product service system from system architecture perspectives. Advances in Decision Sciences, vol. 2012, pp. 1-19, 2012.

Mont, O. Clarifying the concept of product-service system. Journal of Cleaner Production 10, pp. 237-245, 2002.

Mont, O. Reducing life-cycle environmental impacts through systems of joint use. GMI 45 Sring 2004, pp. 63-77, 2004.

Morelli, N. Developing new product service systems (PSS): methodologies and operational tools. Journal of Cleaner Production 14, pp. 1495-1501, 2006.

Partidário, P. J. System assessment. In: Manzini, E.; Collina, L.; Evans, S.; editors. Solution oriented partnership: how to design industrialised sustainable solutions. Milton Keynes: Oscar Press, 2004.

Pezzota, G.; Pinto, R.; Pirola, F.; Ouertanim M-Z. Balancing product-service provider's performance and customer's value: the SErvice Engineering Methodology (SEEM). Procedia CIRP 16, pp. 50-55, 2014. 
Qu, M.; Yu, S.; Chen, D.; Chu, J.; Tian, B. State-of-the-art of design, evaluation, and operational methodologies in product service systems. Computers in Industry 77, pp. 114, 2016.

Reim, W.; Parida, V.; Ortqvist, D. Product-service systems (PSS) business models and tactics - a systematic literature review. Journal of Cleaner Production 97, pp. 61-75, 2015.

Sato, G. S.; Martins, V. A.; Bueno, C. R. F. Análise exploratória do perfil do consumidor de produtos minimamente processados na cidade de São Paulo. Informações Econômicas, São Paulo, jun, v.37, n.6, 2007.

Shehab, E. M.; Roy, R. Product-service systems: issues and challenges. The 4th International Conference on Manufacturing Research (ICMR 2006), pp. 17-22, 2006.

Thyberg, K. L.; Tonjes, D. J. Drivers of food waste and their implications for sustainable policy development. Resources, Conservation and Recycling 106, pp. 110-123, 2016.

Tonelli, F.; Evans, S.; Taticchi, P. Industrial sustainability: challenges, perspectives, actions. Int. J. Business Innovation and Research, vol. 7, n. 2, 2013.

Tukker, A. Eight types of product-service systems: eight ways to sustainability? experiences from SusProNet. Business Strategy and the Environment 13, pp. 246-260, 2004.

Tukker, A. Product services for a resource-efficient and circular economy - a review. Journal of Cleaner Production 97, pp. 76-91, 2015.

Vasantha, G. V. A.; Roy, R.; Lelah, A.; Brissaud, D. A review of product-service systems design methodologies. Journal of Engineering Design, 23:9, pp. 635-659, 2012.

Wang, P. P.; Ming, X. G.; Li, D.; Kong, F. B.; Wang, L; Wu, Z. Y. Status review and research strategies on product-service systems. International Journal of Production Research, 49:22, pp. 6863-6883, 2011.

Warner, M. A new look at institutional food service management. Hospitaliry Review, vol. 10, issue 1, pp. 27-39, 1992.

Weidmann, D.; Maisenbacher, S.; Kasperek, D.; Maurer, M. Product-service system development with discrete event simulation - Modeling dynamic behavior in productservice systems. 2015 IEEE, 2015.

Wrasse, K.; Hayka, H.; Stark, R. Simulation of product-service-systems piloting with agent-based models. Procedia CIRP 30, pp. 108-113, 2015. 
ANEXO A - Tela de Parâmetros de Simulação do Cenário 1 no ProModel.

\begin{tabular}{|c|c|c|c|c|c|c|c|c|}
\hline 阿 Chegadas & & & & & & [1] & 回E & \\
\hline Entidade... & Local.... & Quantidade .... & Primeira Vez.... & Ocorrências & Freqüência & Lógica... & Desab. & \\
\hline vegetais_in_natura_1 & Estoque_MP_1 & 1500 & & 30 & 1440 & & Não & $\hat{\imath}$ \\
\hline vegetais_in_natura_1 & Estoque_MP_1_2 & 1000 & & 30 & 1440 & & Não & $y$ \\
\hline
\end{tabular}

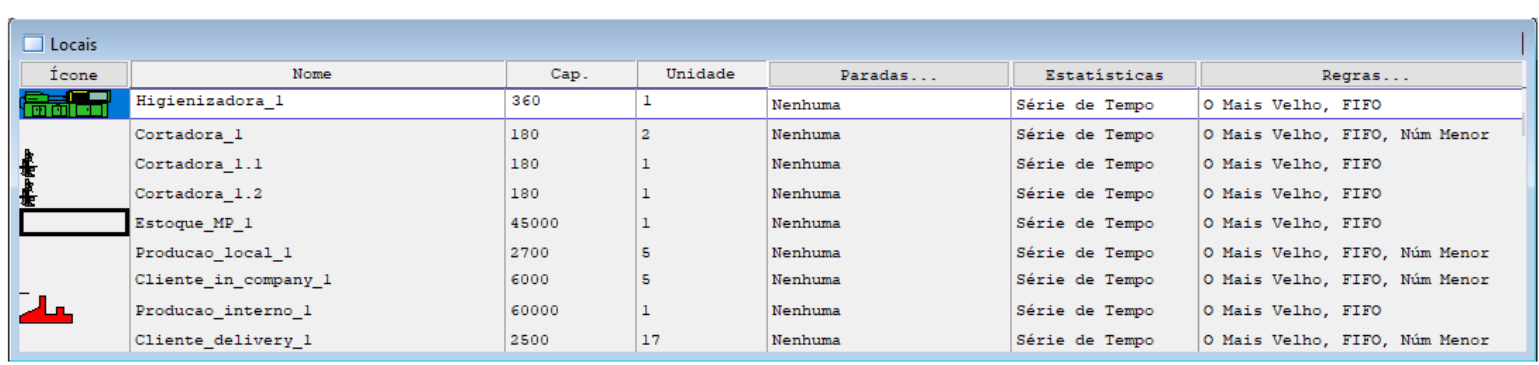

\begin{tabular}{|c|c|c|c|c|c|c|c|c|c|c|}
\hline \multicolumn{8}{|c|}{8 Recursos } & \multicolumn{3}{|c|}{ [1] $\square, x$} \\
\hline Ícone & Nome & Unid. & Paradas... & Estatísticas & Ispecificações & Pesquisar... & Lógica... & Pts... & Anotações... & \\
\hline a & ASG_higienizacao & 4 & Relógio & Por Unidade & delivery_1, R2 & Nenhuma & 0 & 1 & & $\hat{\imath}$ \\
\hline 6 & ASG_corte & 2 & Relógio & Por Unidade & delivery_1， R3 & Nenhuma & 0 & 1 & & \\
\hline & ASG_estoque & 2 & Relógio & Por Unidade & delivery_ $1, R 4$ & Nenhuma & 0 & 1 & & \\
\hline & ASG_cliente & 10 & Relógio & Por Unidade & in_company_1, & Nenhuma & 0 & 1 & & \\
\hline (2) & cozinheiro & 4 & Relógio & Por Unidade & delivery_ 1, RS & Nenhuma & 0 & 1 & & \\
\hline דוד & transporte_delivery & 17 & Nenhuma & Por Unidade & delivery_1, Re & Nenhuma & 0 & 1 & & ע \\
\hline
\end{tabular}

\begin{tabular}{|c|c|c|c|c|c|c|c|}
\hline \multicolumn{3}{|l|}{$\Longrightarrow$ Processo } & \multicolumn{5}{|c|}{$\Longrightarrow$ Roteamento Para vegetais_in_natura_1 @ Estoque_MP_1 } \\
\hline Entidade... & Local... & Operação. & B1 & Saída... & Destino... & & Lógica de Movimento \\
\hline vegetais_in_natura_1 & Estoque_MP_1 & wait 5 & 1 & vegetais_in_natura_1 & Higienizadora_1 & FIRST 1 & Move With ASG_higienizacac \\
\hline vegetais_in_natura_1 & Higienizadora_1 & Wait 6 & & & & & \\
\hline vegetais_in_natura_1 & Producao_local_1 & Wait 120 & & & & & \\
\hline vegetais_processados_ 1 & Estoque_produto_acabad & d Wait SCombine 40 & & & & & \\
\hline vegetais_processados_ 1 & Producao_interno_1 & Wait 60 & & & & & \\
\hline vegetais_in_natura_1 & Estoque_MP_1_2 & Wait 5Combine 20 & & & & & \\
\hline
\end{tabular}


ANEXO B - Tela de Parâmetros de Simulação do Cenário 2 no ProModel.

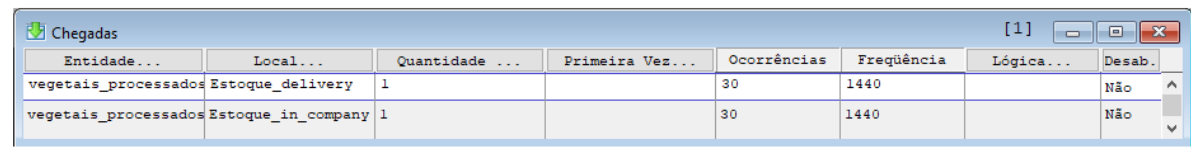

\begin{tabular}{|c|c|c|c|c|c|c|}
\hline \multicolumn{7}{|l|}{$\square$ Locais } \\
\hline Icone & Nome & Cap. & Unidade & Paradas... & Estatísticas & Regras.... \\
\hline & Estoque_in_company & 15000 & 1 & Nenhuma & Série de Tempo & O Mais Velho, FIFO \\
\hline \multirow{10}{*}{ 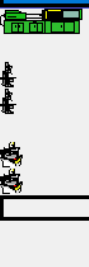 } & Higienizadora_ ${ }^{2}$ & 360 & 1 & Nenhuma & Série de Tempo & O Mais Velho, FIFO \\
\hline & Cortadora_ ${ }^{2}$ & 180 & 2 & Nenhuma & Série de Tempo & o Mais Velho, FIFO, Núm Menor \\
\hline & Cortadora_2.1 & 180 & 1 & Nenhuma & Série de Tempo & O Mais Velho, FIFO \\
\hline & Cortadora_-2.2 & 180 & 1 & Nenhuma & Série de Tempo & ○ Mais Velho, FIFO \\
\hline & Imbaladora_2 2 & 120 & 2 & Nenhuma & Série de Tempo & O Mais Velho, FIFo, Núm Menor \\
\hline & Embaladora_ 2.1 & 120 & 1 & Nenhuma & Série de Tempo & O Mais Velho, FIFO \\
\hline & Embaladora_ 2.2 & 120 & 1 & Nenhuma & Série de Tempo & O Mais Velho, FIFO \\
\hline & |Estoque_produto_acabado_2 & 10800 & 1 & Nenhuma & Série de Tempo & O Mais Velho, FIFO \\
\hline & Cliente_in_company_ 2 & 6000 & 5 & Nenhuma & Série de Tempo & O Mais Velho, FIFo, Núm Menor \\
\hline & C1iente_delivery_ 2 & 2500 & 17 & Nenhuma & Série de Tempo & o Mais Velho, FIFo, Núm Menor \\
\hline
\end{tabular}

\begin{tabular}{|c|c|c|c|c|c|c|}
\hline 8 Recursos & & & & & [1] & $a-x$ \\
\hline Ícone & Unid. & Paradas & Istatísticas specificaçõ̋ ?esquisar & Lógica. & Pts.. & Anotações. \\
\hline ASG_delivery & 8 & Relógio & Por Unidade delivery, $R \lessgtr$ Nenhuma & 0 & 0 & A \\
\hline ASG_in_company & 10 & Relógio & Por Unidade in_company, Nenhuma & 0 & 0 & 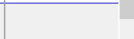 \\
\hline cozinheiro & 4 & Relógio & Por Unidade delivery, $R \in$ Nenhuma & 0 & 0 & \\
\hline transporte_delivery & 17 & Nenhuma & Por Unidade de 1ivery, R? Nenhuma & 0 & 0 & \\
\hline transporte_in_company & 2 & Nenhuma & Por Unidade in_company, Nenhuma & 0 & 0 & 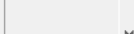 \\
\hline
\end{tabular}

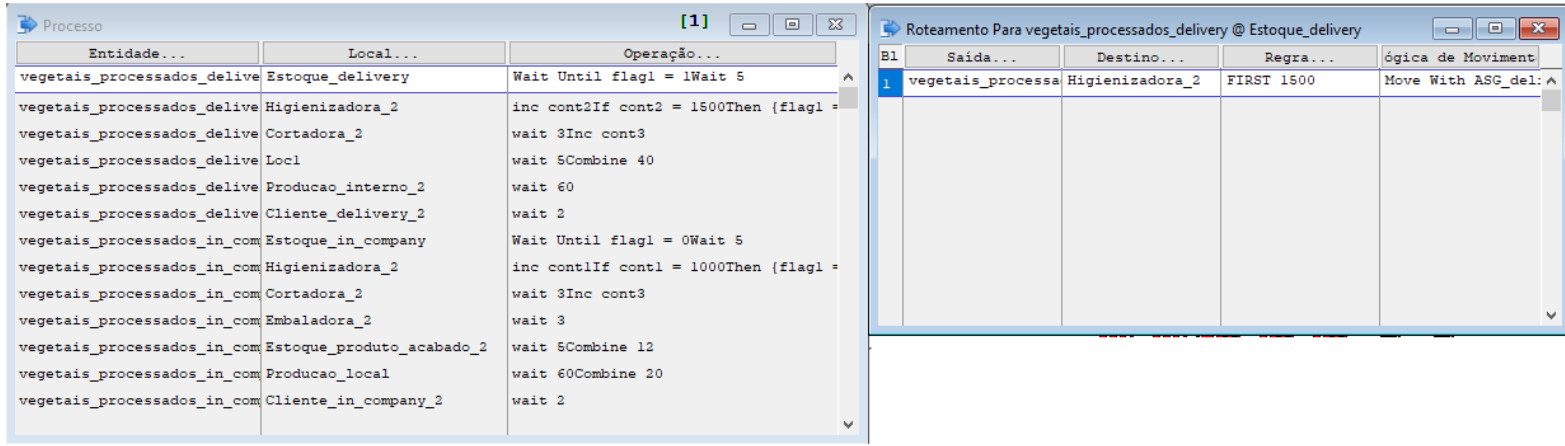


ANEXO C - Tela de Parâmetros de Simulação do Cenário 3 no ProModel.

\begin{tabular}{|c|c|c|c|c|c|c|c|c|}
\hline \multicolumn{6}{|l|}{ 连 Chegadas } & \multicolumn{3}{|c|}{ [1] $\square, x$} \\
\hline Entidade. & Local.... & Quantidade & Primeira Vez... & Ocorrências & Freqüência & Lógica. & Desab. & \\
\hline vegetais_in_natura & Estoque_MP & 2200 & & 30 & 1440 & & Não & A \\
\hline & & & & & & & & $v$ \\
\hline
\end{tabular}

\begin{tabular}{|c|c|c|c|c|c|c|}
\hline \multicolumn{7}{|l|}{$\square$ Locais } \\
\hline Ícone & Nome & Cap. & Unidade & Paradas... & Estatísticas & Regras. \\
\hline & Estoque_MP & 30000 & 2 & Nenhuma & Série de Tempo & o Mais Velho, FIFo, Núm Menor \\
\hline & Estoque_MP. I & 30000 & 1 & Nenhuma & Série de Tempo & 0 Mais Velho, FIFO \\
\hline & Estoque_MP.2 & 30000 & 1 & Nenhuma & Série de Tempo & O Mais Velho, FIFO \\
\hline 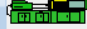 & Higienizadora & 360 & 1 & Nenhuma & Série de Tempo & 0 Mais Velho, FIFO \\
\hline & Cortadora & 180 & 4 & Nenhuma & Série de Tempo & o Mais Velho, FIFo, Núm Menor \\
\hline \& & Cortadora. 1 & 180 & 1 & Nenhuma & Série de Tempo & 0 Mais Velho, FIFO \\
\hline f & Cortadora. 2 & 180 & 1 & Nenhuma & Série de Tempo & 0 Mais Velho, FIFO \\
\hline$t$ & Cortadora. 3 & 180 & 1 & Nenhuma & Série de Tempo & o Mais Velho, FIFO \\
\hline \& & Cortadora. 4 & 180 & 1 & Nenhuma & Série de Tempo & 0 Mais Velho, FIFO \\
\hline & Embaladora & 360 & 4 & Nenhuma & Série de Tempo & O Mais Velho, FIFo, Núm Menor \\
\hline 5 & Embaladora. 1 & 360 & 1 & Nenhuma & Série de Tempo & O Mais Velho, FIFO \\
\hline 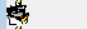 & Embaladora. 2 & 360 & 1 & Nenhuma & Série de Tempo & 0 Mais Velho, FIFO \\
\hline 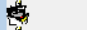 & Embaladora. 3 & 360 & 1 & Nenhuma & Série de Tempo & 0 Mais Velho, FIFO \\
\hline 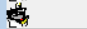 & Embaladora.4 & 360 & 1 & Nenhuma & Série de Tempo & O Mais Velho, FIFo \\
\hline & | Estoque_produto_acabado & 27000 & 1 & Nenhuma & Série de Tempo & 0 Mais Velho, FIFO \\
\hline & Cliente_in_company & 6000 & 5 & Nenhuma & Série de Tempo & O Mais Velho, FIFO, Núm Menor \\
\hline & Cliente_delivery & 2500 & 17 & Nenhuma & Série de Tempo & O Mais Velho, FIFo, Núm Menor \\
\hline
\end{tabular}

\begin{tabular}{|c|c|c|c|c|c|c|c|}
\hline 3 Recursos & & & & & & [1] & $a-x$ \\
\hline Écone & Unid. & Paradas. & :statística pecificaçõo & - lesquisar. & Lógica. & Pts. & Anotações.. \\
\hline ASG & 26 & Relógio & Por Unidad padrao, R2, & Nenhuma & 0 & 1 & A \\
\hline 3 cozinheiro & 4 & Relógio & Por Unidad delivery, $R$ & 2. Nenhuma & 0 & 1 & \\
\hline transporte_delivery & 17 & Nenhuma & Por Unidad delivery, $R$ & 8. Nenhuma & 0 & 1 & \\
\hline transporte_in_company & 3 & Nenhuma & Por Unidad in_company, & , Nenhuma & 0 & 1 & \\
\hline A transporte_varejo & 1 & Nenhuma & Por Unidad varejo, $R 6$ & Nenhuma & 0 & 1 & \\
\hline
\end{tabular}

\begin{tabular}{|c|c|c|c|c|c|c|c|c|}
\hline \multicolumn{2}{|l|}{$\$$ Processo } & \multicolumn{2}{|c|}{ [1] $\square$ 口 83} & \multicolumn{4}{|c|}{ 5) Roteamento Para vegetais_in_natura @ Estoque_MP } & 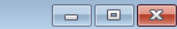 \\
\hline Entidade. & Local. & Operação. & & B1 & Saída. & Destino. & Regra $\ldots$ & ógica de Moviment \\
\hline vegetais_in_natura & Estoque_MP & wait 5 & $\hat{\imath}$ & 1 & vegetais_in_natur & Higienizadora & FIRST 1 & Move with ASG Thei $\wedge$ \\
\hline vegetais_in_natura & Higienizadora & wait $\epsilon$ & & & & & & \\
\hline vegetais_in_natura & Cortadora & wait 3 & & & & & & \\
\hline vegetais_in_natura & Embaladora & wait 3 & & & & & & \\
\hline vegetais_in_natura & Estoque_produto_acabado & Accum 205wait 5Combine 12 & & & & & & \\
\hline vegetais_processados_in_ & Producao_local & wait 60 Combine 20 & & & & & & \\
\hline vegetais_processados_in_ & Cliente_in_company & wait 2 & & & & & & \\
\hline vegetais_processados_de 1 & Producao_interno & wait 60 Combine 40 & & & & & & \\
\hline vegetais_processados_de 1 & Cliente_delivery & wait 2 & & & & & & \\
\hline vegetais_processados_var & Cliente_varejo & wait 2 & $\checkmark$ & & & & & $\checkmark$ \\
\hline
\end{tabular}

